\title{
Adsorptive Removal of Basic Dyes and Hexavalent Chromium from Synthetic Industrial Effluent: Adsorbent Screening, Kinetic and Thermodynamic Studies
}

\author{
Umar Yunusa \\ Department of Pure and Industrial Chemistry, Bayero University, P.M.B.3011, BUK, Kano-Nigeria \\ Email:umaryunusa93@gmail.com \\ Bishir Usman \\ Department of Pure and Industrial Chemistry, Bayero University, P.M.B.3011, BUK, Kano-Nigeria \\ Muhammad Bashir Ibrahim \\ Department of Pure and Industrial Chemistry, Bayero University, P.M.B.3011, BUK, Kano-Nigeria \\ Email: mbibrahim.chm@buk.edu.ng
}

Received: 24 April 2020; Accepted: 23 July 2020; Published: 08 August 2020

\begin{abstract}
The feasibility of utilizing an abundant agricultural waste (desert date seed shell) as an alternative lowcost adsorbent for the removal of hazardous basic dyes [crystal violet (CV) and malachite green (MG)] and hexavalent chromium [Cr(VI)] from synthetic industrial effluent was investigated. Five different adsorbents including the raw, carbonized and chemically activated carbons were prepared and screened with respect to adsorption efficiency of the chosen adsorbates. The prepared adsorbents were characterized using Fourier transform infrared (FTIR) spectroscopy, scanning electron microscopy (SEM) and $\mathrm{pH}$ of zero point charge (pHzpc) analyses. The effects of operational variables such as solution $\mathrm{pH}$, contact time and temperature on adsorption have been investigated. The removal of the adsorbates was found to be highly $\mathrm{pH}$-dependent and the optimum $\mathrm{pH}$ was determined as 8.0 for the dyes and 2.0 for hexavalent chromium. The screening results revealed that the $\mathrm{NaOH}$ activated carbon (NAC) has the best adsorption characteristics with removal efficiencies of 91.10, 99.15 and $91.5 \%$ for $\mathrm{CV}$, MG and $\mathrm{Cr}(\mathrm{VI})$, respectively. The process dynamics was evaluated by pseudo-first-order and pseudosecond-order kinetic models. Experimental data have been found to be well in line with the pseudo-second-order model, suggesting therefore, a chemically-based sorption process. Negative Gibbs free energy change $(\Delta G)$ values obtained from thermodynamic analysis indicated that the adsorption process was spontaneous and had a high feasibility. Positive values for enthalpy change $(\Delta \mathrm{H})$ showed that the removal process was endothermic, implying that the amount of adsorbate adsorbed increased with increasing reaction temperatures. Additionally, positive values of entropy change $(\Delta \mathrm{S})$ reflect the high affinity of the adsorbent material to the adsorbates. On the basis of results and their analyses, it has been established that adsorbent derived from desert date seed shell has a promising potential in environmental applications such as removing hazardous substances from industrial effluents. Through this work, it is believed that contributions are provided to the scientific investigations about the decontamination of precious water resources.
\end{abstract}

Index Terms: Adsorption, Desert date seed shell, Basic dyes, Hexavalent chromium, Kinetics. 


\section{Introduction}

Numerous industrial operations yield liquid effluents which are normally contaminated with toxic or poisonous substances. The textile industry plays a vital role in the global economy as well as in our daily life, but at the same time, it consumes large amount of water and generates huge quantities of wastewaters [1]. The main chemical contaminants present in textile wastewater are synthetic dyes, heavy metals, biocides, pentachlorophenol, free formaldehyde, halogen carriers, softeners and fire retardants [2]. Many reports have highlighted the direct and indirect toxic effects of dyes and heavy metals that can lead to wide range of health problems such as kidney failure, diarrhea, lung cancer, liver damage, asthma and vomiting [3-5]. For these reasons, effluents containing these contaminants should be necessarily treated before discharging to the recipient environment to avoid consequent health problems.

Crystal violet (CV) and malachite green (MG) are basic dyes that belong to the triphenyl methane family of dyes. They are the brightest and most widely used coloring substances among all other dyes of their category. On the other hand, many hexavalent chromium compounds are used in different industrial context and enter the precious water sources whenever they are indiscriminately discarded. In many nations, environmental policies have required that zero synthetic chemicals should be discharged into the aquatic environment.

Various studies were devoted to decontamination of industrial effluent, and have majorly concentrated on the development of an efficient and cost-effective remediation process. These include physicochemical methods such as reverse osmosis, complexation, photocatalysis, sedimentation, ozonation, coagulation, chemical flocculation, precipitation, ion exchange, membrane processes and electrochemical processes [6]. High energy expenses, laborintensive operation, low efficiency and lack of selectivity are among the key limitations that have made this techniques unpopular. When compared to other treatment approaches, adsorption is regarded as the most popular and versatile method for the removal of pollutants from the viewpoint of high efficiency, inexpensiveness, ease of operation and reusable adsorbent design [7].

Adsorption is a powerful and well established technique for treating domestic and industrial effluents which involves the adhesion of gases, liquid or dissolved solid onto a surface. The substance that adhere or concentrate at the surface is called an 'adsorbate' while the material upon whose surface the adsorption occur is called an adsorbent. However, the selection of suitable adsorbent is always a daunting task. The conventional adsorbents include activated carbon, silica gel, nanomaterials, polymeric adsorbents and some other low cost materials. When adsorption is concerned, kinetic and thermodynamic aspects should be involved to gain more insight about its nature and performance. The kinetic performance of a given adsorbent is of great importance for the pilot application. During adsorption, two major processes are involved; physisorption or chemisorption. Physisorption is as a result of weak van der Waals forces of attraction, while chemisorption involves the formation of a strong chemical bond between the adsorbate and the adsorbent.

The quest for safe and cheap method for the elimination of pollutants from wastewater has necessitated research interest towards the synthesis of low cost alternatives to expensive commercial activated carbon. There are a number of studies showing that agricultural wastes and by-products can be utilized as viable options to remove dye and toxic metals from a given matrix [8]. The advantage of utilizing these wastes is the ability to produce cheap and eco-friendly carbon as substitution to the expensive commercial product. These agricultural materials usually have no economic applications and may present a disposal problem leading to environmental pollution. Thus, appreciable economic gains would be attained through the conversion of these materials into activated carbon.

Desert date (Balanites aegyptiaca) is an evergreen, multi-branched and spiny tree grown in the dry and savannah areas of Africa and south Asia. Practically, all parts of the plant, except perhaps the seed shell, are utilized for purposes best suited to them. One of the abundant agricultural wastes in Nigeria is the desert date seed shell (DDSS) [9]. Because of its woody nature, it resist biodegradation and persist in the environment for a very long time. Therefore, a great benefit can be derived from the use of this abundant and renewable material in the production of value added adsorbents for industrial purposes.

The purpose of the present investigation is to evaluate the efficiency of adsorbents fabricated from desert date seed shell for the removal of basic dyes and hexavalent chromium from synthetic industrial wastewater. The focus of this study is to (1) prepare adsorbents of different properties from DDSS; (2) study the chemical characteristics and morphology of the prepared adsorbents via Fourier transform infrared (FTIR) spectroscopy, scanning electron microscopy (SEM) and $\mathrm{pH}$ of zero point charge $\left(\mathrm{pH}_{\mathrm{zpc}}\right)$ analyses; (3) screen the most efficient adsorbent material by varying the solution $\mathrm{pH}$; and (4) provide kinetic and thermodynamic data, which are important for better understanding of the adsorption mechanism and evaluation of adsorbent efficiency. 


\section{Literature Review}

Magnetic nanoparticle biosynthesized from leaf extract of Fraxinus chinesis Roxb was employed for the removal of crystal violet and eriochrome black $\mathrm{T}$ dyes. The formation of nanoparticles was verified by different techniques such as UV, FTIR, XRD, SEM and EDX. The results showed that the nanoparticles exhibit $>95 \%$ removal of both dyes with 10 minutes of contact time over a wide range of concentration, $10-300 \mathrm{mg} \mathrm{dm}^{-3}$. The degradation kinetics indicated that the kinetic data for both crystal violet and Eriochrome Black $\mathrm{T}$ followed firstorder degradation rate [10].

Tectona grandis sawdust (TGSD) was explored as an efficient adsorbent for the decontamination of crystal violet (CV) dye from wastewater. The adsorption capacity was observed to be increased with increasing $\mathrm{pH}$ of the medium up to a value of 7.0 and thereafter it remains almost stagnant on a further increase of pH. Equilibrium time for adsorption of CV onto TGSD was found to be 180 min. Kinetic study revealed that adsorption was best described by pseudo-second-order kinetics. Adsorption equilibrium data were found to be best fitted by Langmuir isotherm model and the maximum equilibrium adsorption capacity was observed to be $131.58 \mathrm{mg} \mathrm{g}^{-1}$. The thermodynamic study showed that the decontamination of CV by TGSD was spontaneous, endothermic and associated with an increase in entropy [11].

Adeyi et al. [12] investigated the adsorption capacities of thiourea-modified poly(acrylonitrile-co-acrylic acid) (TU-poly(AN-co-AA)) using malachite green (MG) as an adsorbate. Results obtained showed that maximum MG removal was observed at $\mathrm{pH}$ 11. Kinetic studies revealed that the pseudo-second-order model best described the adsorption process. The equilibrium isotherm has its fitness in the following order: Freundlich model $>$ Temkin model> Langmuir model and the maximum adsorption capacity was found to be $269.54 \mathrm{mg} \mathrm{g}^{-1}$. Thermodynamic analysis indicates that the sorption process is spontaneous and exothermic in nature.

Sriram et al. [13] reported the use of porous silica diatomaceous earth (DE) microparticles for malachite green removal applications. The surface of DE was functionalized by different concentration of silica-xerogel to enhance dye removal efficiency. Mechanism of MG adsorption by the adsorbents were studied and the adsorption process followed Freundlich $\left(\mathrm{R}^{2}=0.972\right)$ isotherm which correspond to multilayer adsorption. Kinetic studies showed higher correlation for pseudo-second-order $\left(\mathrm{R}^{2}=0.999\right)$ model.

Asadullah et al. [14] used modified biochar obtained after hydrothermal carbonization of Lepironia articulata for the removal of hexavalent chromium from aqueous solution. The performance of the modified biochar was investigated through batch sorption experiments. Results revealed that removal (\%) and the maximum adsorption capacity $\left(\mathrm{q}_{\max }\right.$ ) of $\mathrm{Cr}(\mathrm{VI})$ onto the adsorbent increased up to $98.9 \%$ and $28.75 \mathrm{mg} \mathrm{g}^{-1}$ relative to $63.44 \%$ and $21.90 \mathrm{mg} \mathrm{g}^{-1}$ in unmodified biochar at $\mathrm{pH} 2.0,313 \mathrm{~K}$, and $200 \mathrm{mg} \mathrm{dm}^{-3}$ respectively. The sorption kinetics uptake data were best interpreted with pseudo-second-order model, and sorption isotherm was simulated with the Langmuir model. The thermodynamic parameters confirm the adsorption process to be endothermic, spontaneous and increased disorder.

In another study, Labied et al. [15] reported the successful removal of Cr (VI) by Zizipus Jujuba rubidium carbonate-activated carbon. Results indicated that the optimal conditions for maximum adsorption efficiency are 2.0 for $\mathrm{pH}, 1 \mathrm{~g} \mathrm{dm}^{-3}$ for activated carbon dosage and $100 \mathrm{mg} \mathrm{dm}^{-3}$ for Cr (VI) concentration. The kinetic sorption was described by a pseudo-second order kinetic equation. The Toth and Elovich models were best to explain the adsorption phenomenon. Thermodynamic studies showed that the adsorption process was feasible, spontaneous and endothermic at $20-40^{\circ} \mathrm{C}$.

\section{Materials and Methods}

\subsection{Dyes and Chemicals}

Crystal violet $\left(\mathrm{C}_{25} \mathrm{H}_{30} \mathrm{~N}_{3} \mathrm{Cl}, 407.98 \mathrm{~g} \mathrm{~mol}^{-1}\right.$, CI 42555) and Malachite green $\left(\mathrm{C}_{23} \mathrm{H}_{25} \mathrm{~N}_{2} \mathrm{Cl}, 364.92 \mathrm{~g} \mathrm{~mol}^{-1}\right.$, CI 42000) were purchased from E. Merck (Mumbai, India). Potassium dichromate $\left(\mathrm{K}_{2} \mathrm{Cr}_{2} \mathrm{O}_{7}\right)$, zinc chloride $\left(\mathrm{ZnCl}_{2}\right)$, phosphoric acid $\left(\mathrm{H}_{3} \mathrm{PO}_{4}\right)$, sodium nitrate $\left(\mathrm{NaNO}_{3}\right)$, sodium hydroxide $(\mathrm{NaOH})$ and hydrochloric acid $(\mathrm{HCl})$ used were of analytical grade sourced from Sigma-Aldrich. De-ionized water was employed in all experiments and dilutions. 


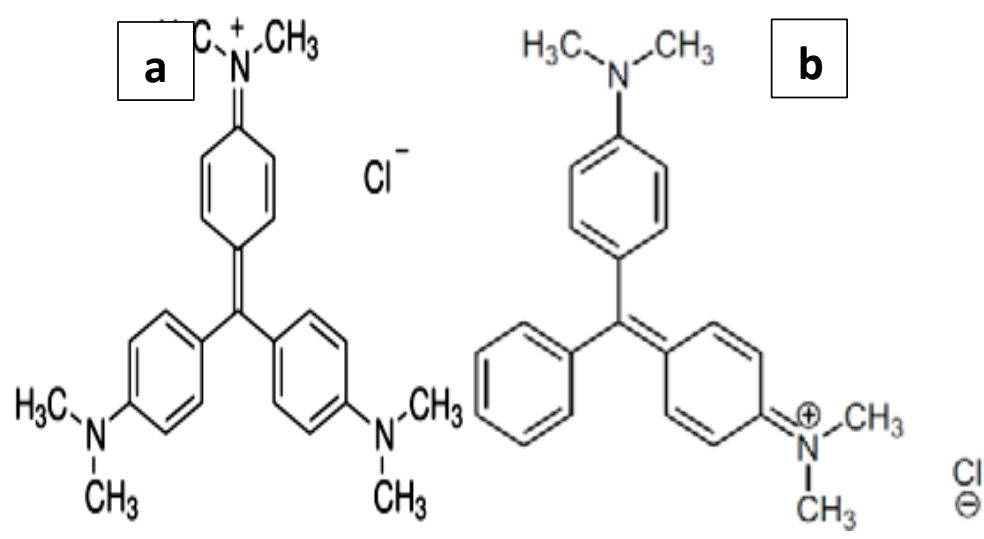

Fig. 1. Molecular structures of (a) crystal violet (b) malachite green

\subsection{Preparation of Synthetic Wastewater}

Dye stock solutions (1000 $\mathrm{mg} \mathrm{dm}^{-3}$ ) were prepared by dissolving $1 \mathrm{~g}$ (each) of the respective dyes in 100 $\mathrm{cm}^{3}$ beaker and made up to $1000 \mathrm{~cm}^{3}$ in a volumetric flask with de-ionized water. The $\operatorname{Cr}(\mathrm{VI})$ stock solution was prepared by dissolving $2.829 \mathrm{~g}$ of potassium dichromate in $1000 \mathrm{~cm}^{3}$ deionized water. The needed experimental concentrations were prepared by appropriate dilution of the stock with deionized water.

\subsection{Adsorbents}

In the present study, five different adsorbents were fabricated from desert date seed shell (DDSS) to adsorb the preselected basic dyes and hexavalent chromium from the aqueous medium using batch adsorption processes. These adsorbents include the: raw sample (DDSS), carbonized sample (CDDSS), $\mathrm{NaOH}$ activated carbon (NAC), $\mathrm{ZnCl}_{2}$ activated carbon (ZAC) and $\mathrm{H}_{3} \mathrm{PO}_{4}$ activated carbon (HAC).

\subsection{Sample Collection and Treatment}

Desert date seed shells (DDSS) were sourced from a local market in Gashua-Yobe, Nigeria. The shells were first washed thoroughly with water to get rid of dust and surface adhered impurities. They were subsequently air-dried for $72 \mathrm{~h}$ and then in an oven at $105^{\circ} \mathrm{C}$ for $24 \mathrm{~h}$. The dried shells were ground and screened through a sieve to obtain a particle size of less than $300 \mu \mathrm{m}$. Finally, the powdered sample was stored in an air-tight container and used as an adsorbent without any further treatment.

\subsection{Preparation of Activated Carbon}

Activated carbons were prepared from DDSS using a two-step chemical activation technique, as described by Wang et al. [16], but with modification in the activating agents used $\left(\mathrm{H}_{3} \mathrm{PO}_{4}, \mathrm{NaOH}\right.$ and $\mathrm{ZnCl}_{2}$ instead of $\left.\mathrm{KOH}\right)$. The dried DDSS were carbonized at $700^{\circ} \mathrm{C}$ in a furnace for 90 minutes (first pyrolysis). The carbonized sample (CDDSS) was then impregnated with solutions of the aforementioned activators in three separate beakers such that the mass ratio of the activator to charcoal was 2:1. This was followed by further thermal treatment in a furnace (second pyrolysis) at $750^{\circ} \mathrm{C}$ for 90 minutes. The sample was cooled, leached with $0.1 \mathrm{M} \mathrm{HCl}$ and then thoroughly washed with distilled water until a neutral $\mathrm{pH}(\approx 6.9)$ was attained. The desired activated carbon was obtained after drying in an oven at $110^{\circ} \mathrm{C}$ for $24 \mathrm{~h}$. 


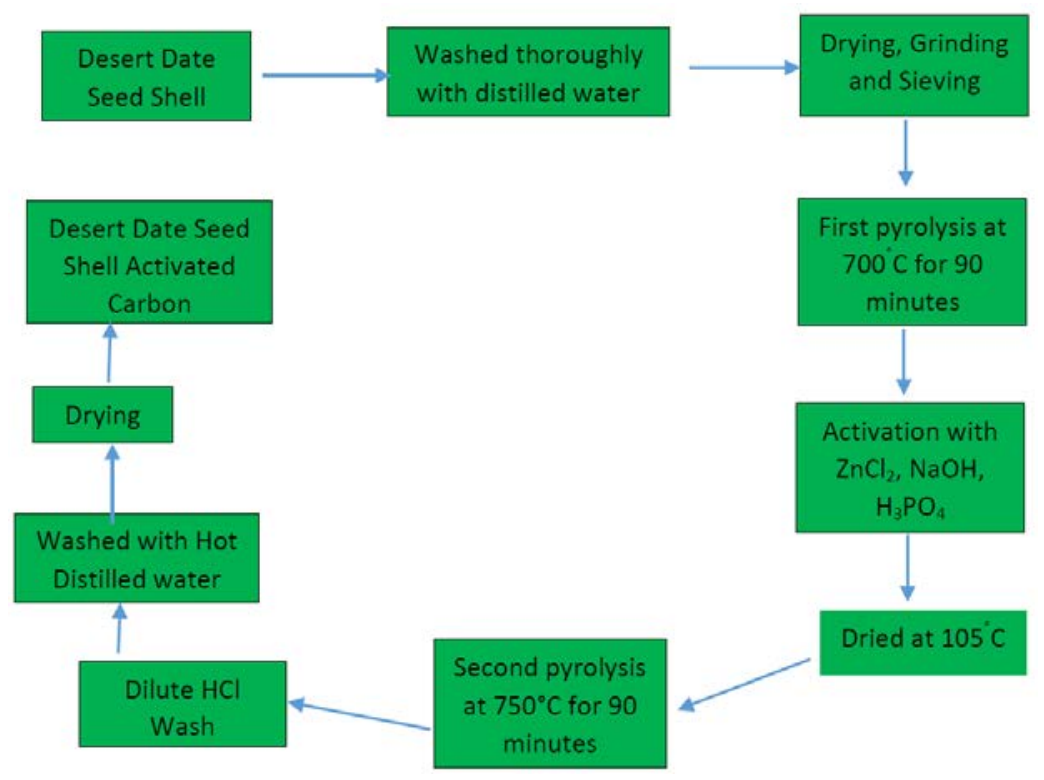

Fig. 2. Flow chart for the preparation of desert date seed shell activated carbon

\subsection{Characterization Techniques}

The prepared adsorbents were characterized by FTIR, SEM and $\mathrm{pH}_{\mathrm{zpc}}$ analyses. The FTIR spectra were recorded on an Agilent FTIR spectrometer (Cary 630). SEM micrograghs were obtained with Phenomn scanning electron microscope (PRO: X: Phenonm World 800-07334). The $\mathrm{pH}$ of zero charge point $\left(\mathrm{pH}_{\mathrm{zpc}}\right)$ of the adsorbents was determined according to the salt addition method described by Bakatula et al. [17].

\subsection{Adsorption Experiment}

Adsorbate solutions $\left(100 \mathrm{~cm}^{3}\right.$ each) were added into $250 \mathrm{~cm}^{3}$ conical flasks. The initial $\mathrm{pH}$ of the respective solutions were adjusted to desired value using $0.1 \mathrm{M} \mathrm{HCl}$ and $0.1 \mathrm{M} \mathrm{NaOH}$. Subsequently, a certain amount of each of the prepared adsorbents was added to the solutions, except for the control sample where no adsorbent was added. The samples were then agitated at $150 \mathrm{rpm}$ in an orbital incubator shaker at $30^{\circ} \mathrm{C}$ for $60 \mathrm{~min}$. The samples were subsequently filtered, centrifuged and the residual concentrations of the adsorbates were analyzed. Based on the removal efficiency, the most promising adsorbent was selected to undergo the further optimization of process variables such as contact time (5-120 min) and temperature (303-333K). The extent of adsorbate adsorption was calculated by using the following equations:

$$
\begin{aligned}
\mathrm{qe} & =\left(\frac{\mathrm{Co}-\mathrm{Ce}}{\mathrm{m}}\right) \mathrm{V} \\
\mathrm{qt} & =\left(\frac{\mathrm{Co}-\mathrm{Ct}}{\mathrm{m}}\right) \cdot \mathrm{V} \\
\mathrm{R}(\%) & =\left(\frac{\mathrm{Co}-\mathrm{Ce}}{\mathrm{Co}}\right) \times 100
\end{aligned}
$$

where; $\mathrm{q}_{\mathrm{e}}$ is the equilibrium adsorption capacity $\left(\mathrm{mg} \mathrm{g}^{-1}\right), \mathrm{q}_{\mathrm{t}}$ is the adsorption capacity at any given time $\mathrm{t}\left(\mathrm{mg} \mathrm{g}^{-1}\right)$, $\mathrm{R}(\%)$ is the percent removal, $\mathrm{C}_{0}$ is the initial concentration of adsorbate $\left(\mathrm{mg} \mathrm{dm}^{-3}\right), \mathrm{C}_{\mathrm{e}}$ is the concentration of adsorbate at equilibrium $\left(\mathrm{mg} \mathrm{dm}^{-3}\right), \mathrm{C}_{\mathrm{t}}$ is the concentration of adsorbate at time $\mathrm{t}\left(\mathrm{mg} \mathrm{dm}^{-3}\right), \mathrm{V}$ is the initial volume of adsorbate solution $\left(\mathrm{dm}^{3}\right)$ and $\mathrm{m}$ is the mass of the adsorbent $(\mathrm{g})$.

\subsubsection{Effect of $p H$}

The effect of solution $\mathrm{pH}$ on sorption process was investigated over a $\mathrm{pH}$ range of 2.0-10.0. A $100 \mathrm{~cm}^{3}$ of sample solution of fixed concentration $\left(100 \mathrm{mg} \mathrm{dm}^{-3}\right)$ was contacted with $0.2 \mathrm{~g}$ of the adsorbent. The mixtures were agitated for $60 \mathrm{~min}$ at $30^{\circ} \mathrm{C}$. After centrifugation, the supernatant was analyzed for residual adsorbate concentration. 


\subsubsection{Effect of contact time}

A series of $100 \mathrm{~cm}^{3}$ of the adsorbate solution of fixed concentration $\left(100 \mathrm{mg} \mathrm{dm}^{-3}\right)$ were taken in different conical flask and a fixed amount of adsorbent $(0.15 \mathrm{~g})$ was added to each flask. The contents were allowed to agitate at $150 \mathrm{rpm}$ in an incubator shaker (303K) for varying time interval of 5, 10, 20, 30, 40, 50, 60, 90 and 120 min. The solutions after each time interval were filtered immediately, centrifuged and subjected to analysis.

\subsubsection{Effect of Temperature}

For the influence of temperature, $0.15 \mathrm{~g}$ of adsorbent was added into $100 \mathrm{~cm}^{3}$ of adsorbate solutions (100 $\mathrm{mg} \mathrm{dm}^{-3}$ ). Batch experiments were performed at different temperatures of 303, 313, 323, and $323 \mathrm{~K}$ while keeping the rest of the experimental parameters constant. After each adsorption experiment, residual concentrations of adsorbate were analyzed.

\subsection{Analyses and Data Evaluation}

The residual dye concentration in the supernatant obtained after adsorption was analyzed using Perkin Elmer UV-Vis spectrometer (Labda 35) at maximum absorbance wavelength $\left(\lambda_{\max }\right)$ of $591 \mathrm{~nm}$ and $617 \mathrm{~nm}$ for CV and MG, respectively. In the case of Cr (VI), Agilent Microwave Plasma-Atomic Emission Spectrometer (4210 MPAES) was utilized for the determination of residual concentration. Standard solutions $\left(2-10 \mathrm{mg} \mathrm{dm}^{-3}\right)$ of the adsorbates were prepared and absorbance values were recorded to obtain the calibration curve. The residual concentration of each adsorbate was determined with reference to the respective linear calibration curve by interpolation.

\subsection{Error Analysis}

To ensure correctness, reliability and reproducibility of the obtained data, all the sorption experiments were conducted in triplicate and the results were reported as the mean based on three different experiments. In nearly all instances, the relative standard deviation was less than $2.0 \%$. In the modeling studies, the coefficient of determination $\left(\mathrm{R}^{2}\right)$ and sum of error squares (SSE, \%) were employed to evaluate the suitability of each model. A higher value of $\mathrm{R}^{2}$ and lower value of SSE signify better model fitting. The SSE measure the disparity between experimental and model predicted values, and it can be computed by the following equation:

$$
\operatorname{SSE}(\%)=\sqrt{\frac{\sum\left(\mathrm{q}_{\mathrm{e}, \text { exp }}-\mathrm{q}_{\mathrm{e}, \mathrm{cal}}\right) 2}{\mathrm{~N}}}
$$

where $\mathrm{N}$ is the data points number, $\mathrm{q}_{\mathrm{e}, \mathrm{cal}}$ and $\mathrm{q}_{\mathrm{e}, \mathrm{exp}}\left(\mathrm{mg} \mathrm{g}^{-1}\right)$ represent the theoretically and experimentally obtained adsorption capacity, respectively.

\section{Results and Discussion}

\subsection{Morphology Analysis}

Scanning electron microscopy is one the most widely used techniques in materials characterization. The morphological features of the raw (DDSS), carbonized (CDDSS) and activated carbon samples (NAC, ZAC and HAC) were examined by SEM analysis and the result is displayed in Fig. 3. It can be observed in Fig. 3a that the surface of DDSS is highly rough and nonporous with some crevices. However, the micrographs clearly reflected the uneven pore structure of the activated carbon samples. These indicated that the activation of DDSS showed substantial influence on its surface in terms of enhanced porosity and thus can facilitate the binding of the adsorbates. The development of pores was attributed to the volatilization of some organic groups during impregnation and thermal activation

[18]. 

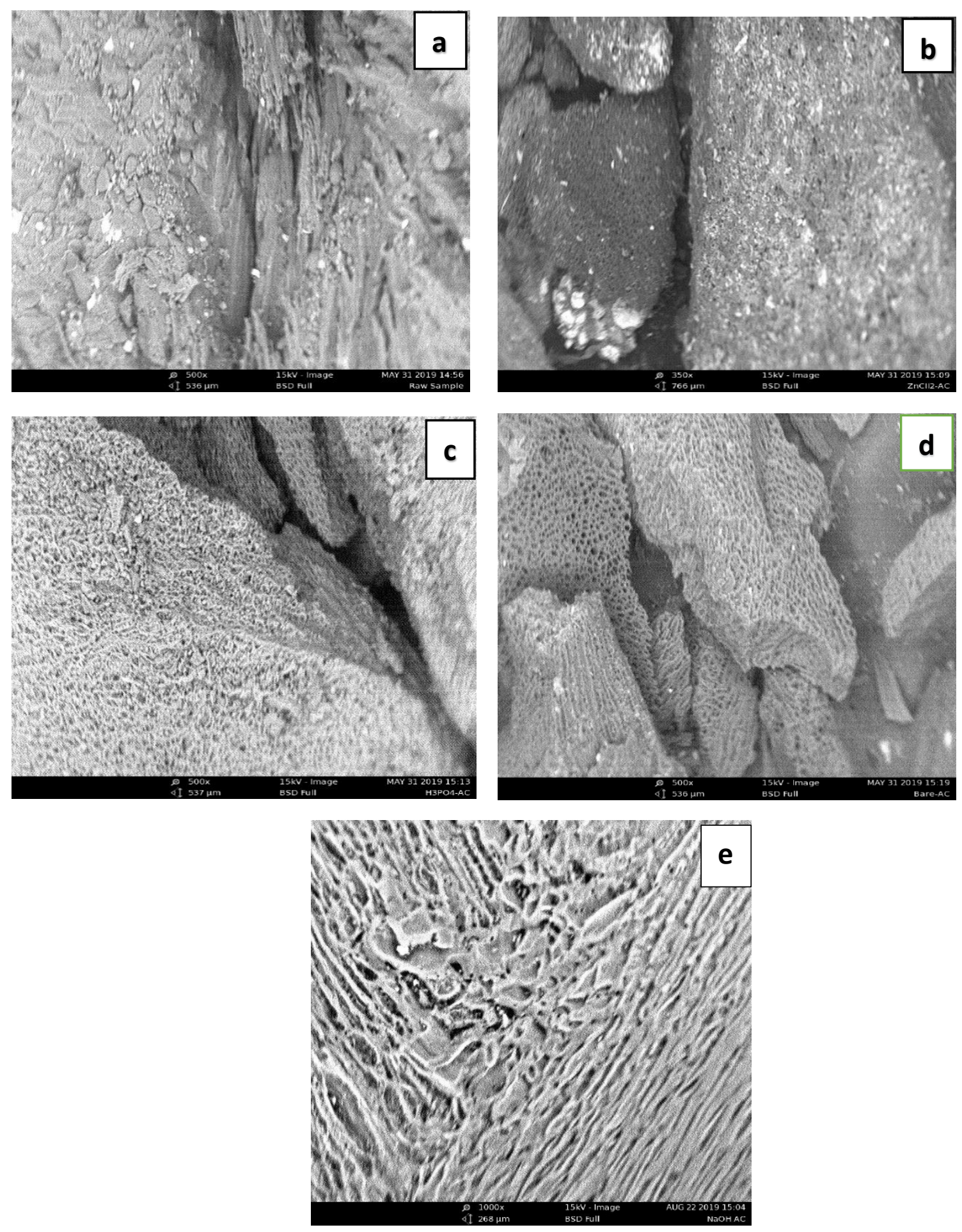

Fig. 3. SEM micrograph of (a) DDSS (b) ZAC (c) HAC (d) NAC (e) CDDSS

\subsection{FTIR Analysis}

FTIR measurements were conducted to identify the interactions and presence of various functional groups that might serve as potential adsorption sites (Fig. 4). The spectroscopic analysis indicated broad band at 3309.97 $\mathrm{cm}^{-1}$ which is ascribable to the stretching frequency of bonded -OH groups [19]. The bands at $2921.96 \mathrm{~cm}^{-1}$ and $2851.97 \mathrm{~cm}^{-1}$ could be attributed to the stretching frequency of $\mathrm{C}-\mathrm{H}$ bond of methyl and methylene groups. The 
absorption peak observed at $1741.97 \mathrm{~cm}^{-1}$ was ascribed due to the carbonyl group $(\mathrm{C}=\mathrm{O})$ of carboxylic acid or ester while the peak at $1640.97 \mathrm{~cm}^{-1}$ was assigned due to the $\mathrm{C}=\mathrm{O}$ stretching of carboxylic acid [20]. The peaks at $1525.84 \mathrm{~cm}^{-1}$ and $1424.97 \mathrm{~cm}^{-1}$ are linked with aromatic ring stretching of lignin and the peak at $1022.92 \mathrm{~cm}^{-1}$ to $1238.96 \mathrm{~cm}^{-1}$ is associated with the C-O bond bending of cellulose, hemicellulose and lignin [21].

Prominent variations were observed between the spectrum of the raw and activated carbon samples as depicted in Fig. 4a. The peak at $1022.92 \mathrm{~cm}^{-1}$ to $1238.96 \mathrm{~cm}^{-1}$ in the spectrum of DDSS is not present in all the activated carbon samples. This indicated that activation of DDSS influenced the already present C-O group of cellulose and hemicellulose. Similarly, the absorption frequency observed at $1741.97 \mathrm{~cm}^{-1}$ and $1640 \mathrm{~cm}^{-1}$ disappeared in all the activated samples. Thus, it can be inferred that the functionality of activated samples has been decreased as compared to the DDSS. This can be attributed to elimination of some organic groups as a result of the pyrolysis during activation.

The FTIR spectrum of the NaOH-AC (NAC) before and after adsorbates adsorption is displayed in Fig. 4b. The peak (before adsorption) situated at $3361 \mathrm{~cm}^{-1}$ which is linked to -OH groups had shifted to 3327, 3272 and $3301 \mathrm{~cm}^{-1}$ after adsorption of CV, MG and $\mathrm{Cr}(\mathrm{VI})$ respectively. This changes in peak position indicates the participation of these groups in the adsorption process. Similarly, the appearance of some new peaks suggest that some interactions occurred between the adsorbent and adsorbates.

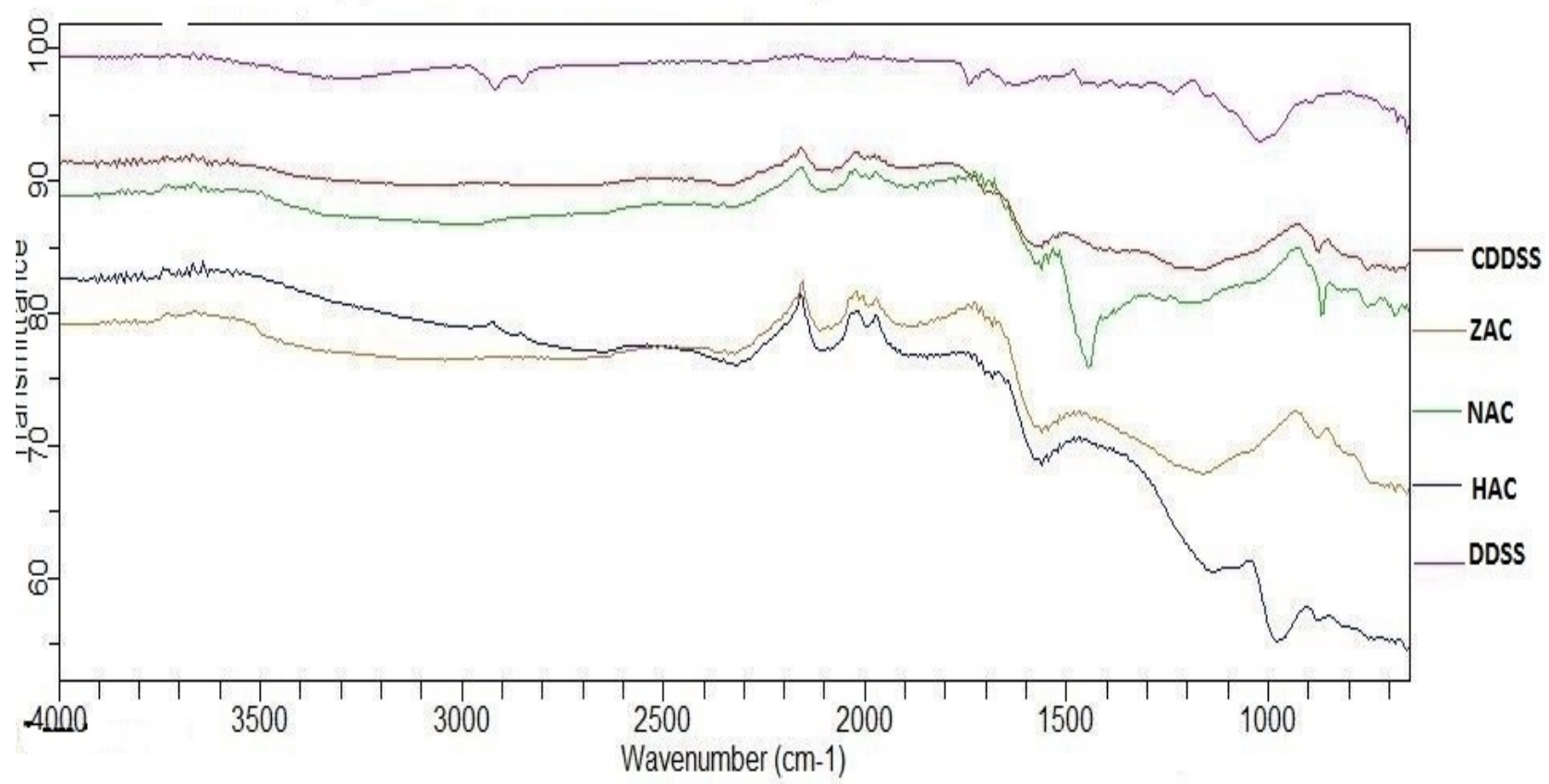

Fig. 4a. FTIR Spectra of Prepared Adsorbents 


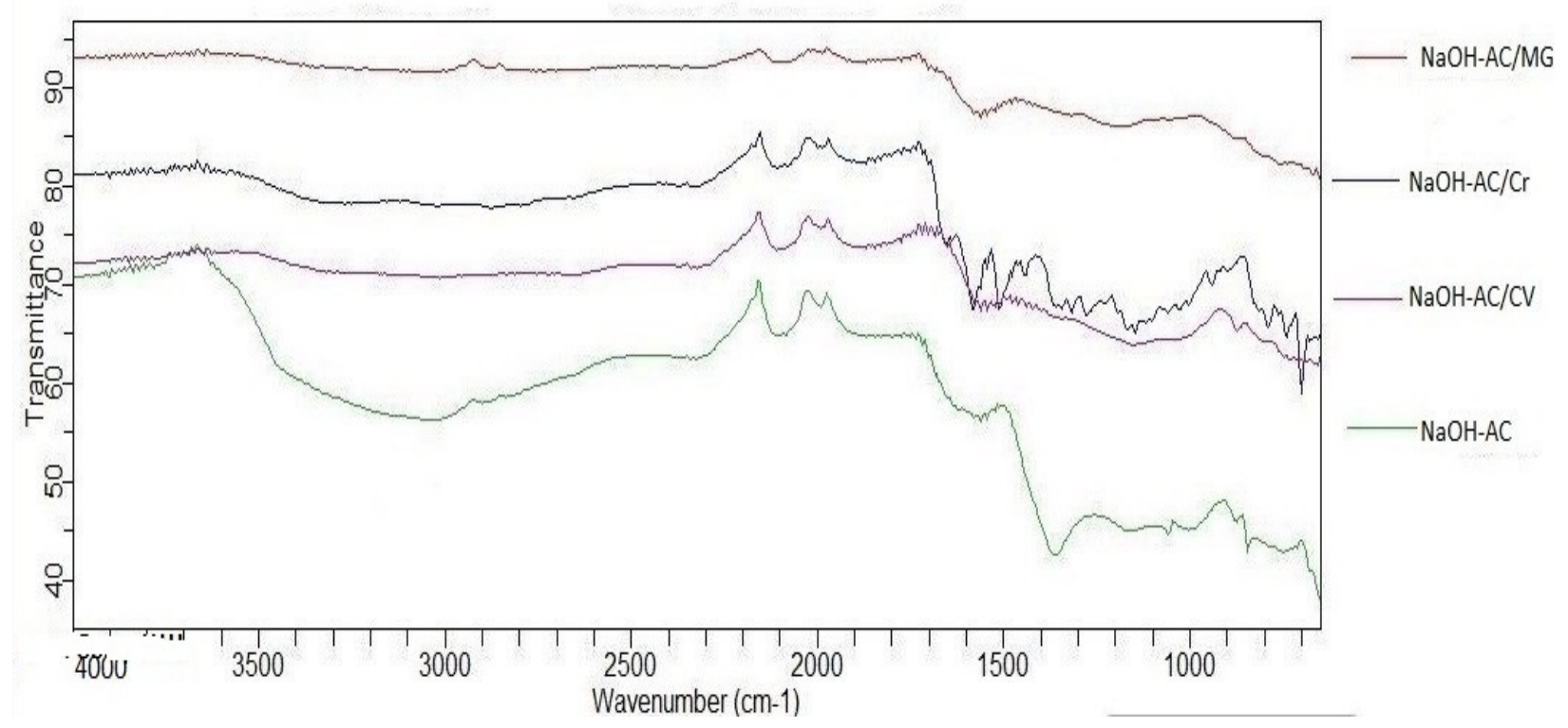

Fig 4b: FTIR Spectra of NaOH-AC before and after adsorption

\section{$4.3 \mathrm{pH}$ of Zero Point Charge (pH zpc) Analysis}

The $\mathrm{pH}$ of zero point charge (also known as isoelectric point) is defined as the $\mathrm{pH}$ at which the surface net charge becomes equal to zero under certain conditions of pressure, temperature and aqueous solution composition. This does not imply that the surface has no charge at $\mathrm{pH}_{\mathrm{pzc}}$, but rather there are equal amount of positive and negative charges. The magnitude of the surface charge depends on the abundance and types of functional groups present, and on the $\mathrm{pH}$ of the solution [22].

$\mathrm{pH}_{\text {zpc }}$ plays an important role in surface characterization as it dictates how easily an adsorbent can bind potentially harmful ions [23]. This is due to the fact that the adsorbent surface bears a net negative charge at $\mathrm{pH}>$ $\mathrm{pH}_{\mathrm{zpc}}$ making the adsorption of cationic species more favourable. Conversely, for $\mathrm{pH}<\mathrm{pH}_{\mathrm{zpc}}$ values, the adsorbent surface bears a net positive charge capable of repelling cations [24].

$\mathrm{pH}$ of zero point charge $\left(\mathrm{pH}_{\mathrm{zpc}}\right)$ values for DDSS, NAC, ZAC and HAC obtained using the salt addition method was found to be 5.9, 6.5, 6.9 and 6.4 respectively (Fig. 5). Comparison of the values showed that after activation, the surface of the DDSS has been altered by the incorporation of activating agent. The surface of the activated carbons become more basic than DDSS as evidenced by the increase in $\mathrm{pH}_{\text {zpc }}$ value. This is attributed to decrease in acidic groups such as carboxylate ion on the surface of the activated carbons as indicated by FTIR data in section 4.2 . 

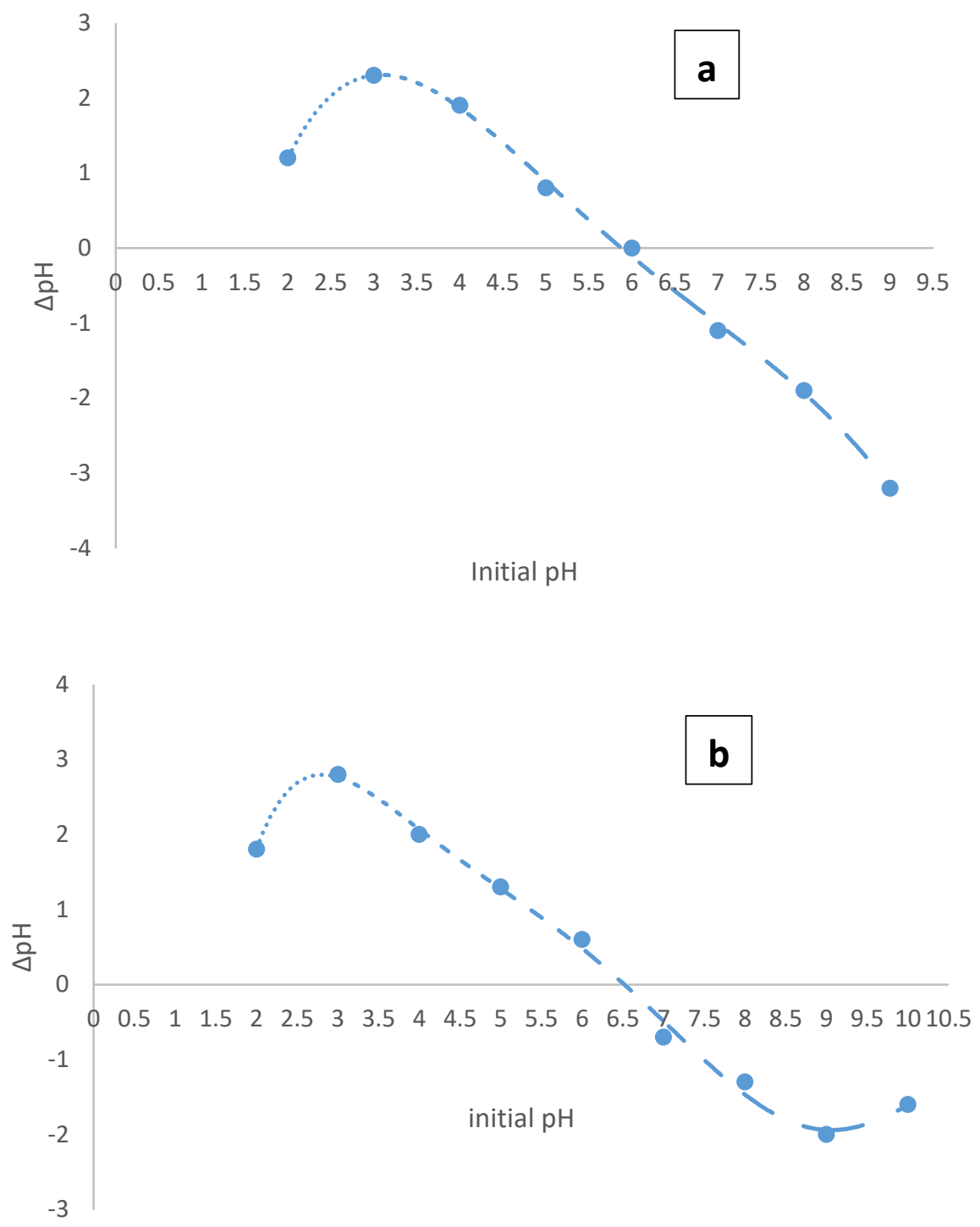

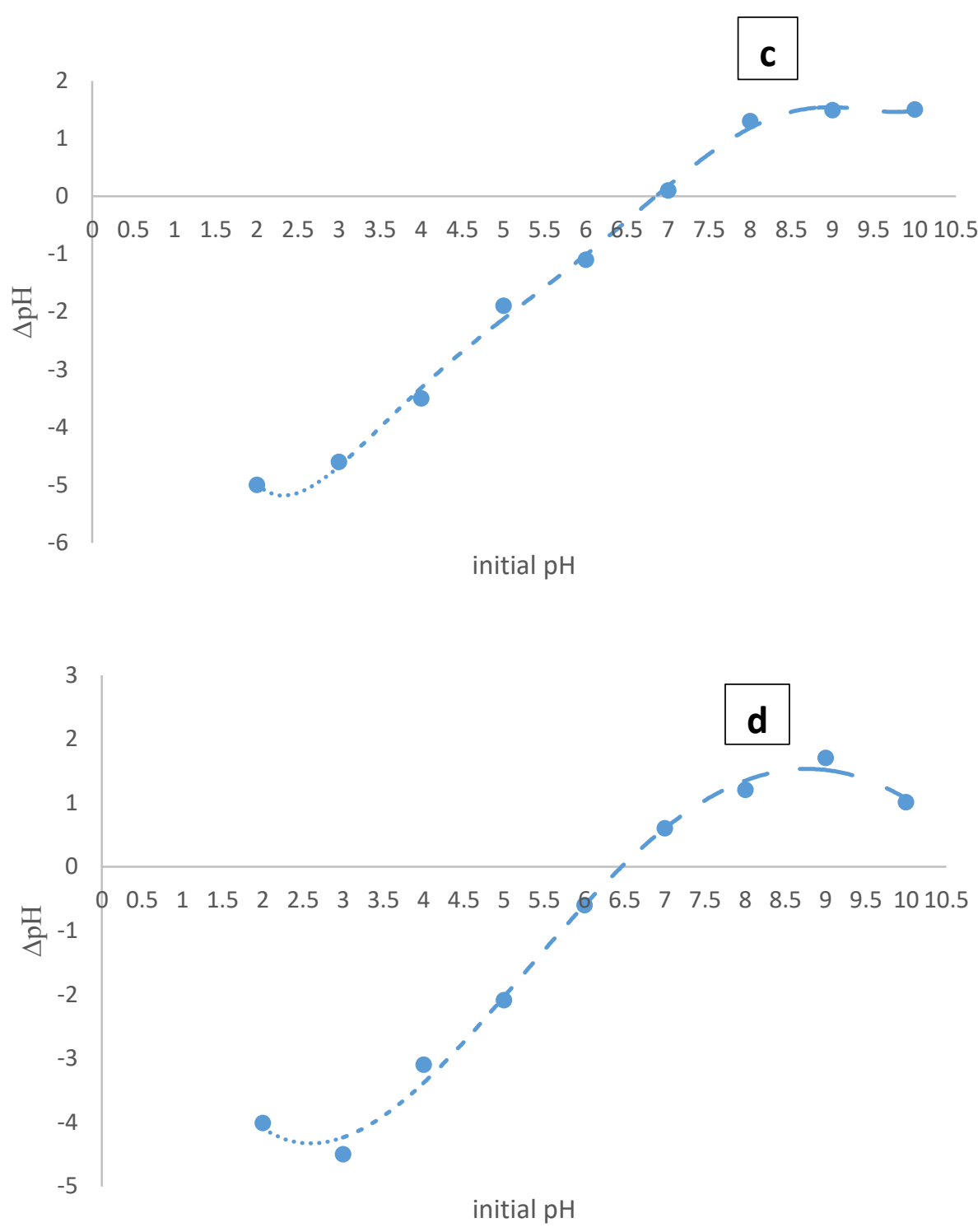

Fig. 5. $\mathrm{pH}_{\text {zpc }}$ plot for (a) DDSS (b) NAC (c) ZAC (d) HAC

\subsection{Effect of $p H$}

$\mathrm{CV}$ and MG are cationic dyes that exist in the form of positively charged ions in aqueous solution. Therefore, as charged species, the rate of their adsorption onto the surface of the adsorbent is primarily controlled by the surface charge on the adsorbent, which in turn is influenced by the solution $\mathrm{pH}$. The effect of solution $\mathrm{pH}$ on the adsorption process was illustrated in Fig. 6. It is obvious that the average removal efficiency of the adsorbents for the adsorbates over all the $\mathrm{pH}$ ranges studied follows the following order: NAC > ZAC > HAC > DDSS > CDDSS. As per selection criteria (section 3.7), the NAC having the highest removal efficiency was selected for further optimization of process variables (contact time and temperature).

It was observed that for CV and MG, the removal efficiency increased from 81.18 and $89 \%$ to 99 and $99.36 \%$ with the increase in solution $\mathrm{pH}$ from 2.0 to 8.0. Thus, the $\mathrm{pH} 8.0$ was taken as the optimum $\mathrm{pH}$ value for all subsequent experiments. At low $\mathrm{pH}$ values, the surface of the adsorbent becomes positively charge by the absorption of $\mathrm{H}^{+}$ions leading to repulsion between cationic dyes and positively charged adsorbent. Also, there is increased competition between dye cations $\left(\mathrm{CV}^{+}\right.$and $\left.\mathrm{MG}^{+}\right)$and protons $\left(\mathrm{H}^{+}\right)$for adsorption sites at a lower $\mathrm{pH}$. On the other hand, in basic medium, due to the presence of $\mathrm{OH}^{-}$ions in excess, the surface of the adsorbent becomes negatively charged. This results in electrostatic attraction between cationic dyes and negatively charged adsorbent surface leading to improved adsorption in basic $\mathrm{pH}$. These observations are in agreement with reported findings $[25,26]$. 
In this context, it is imperative to comment that the significant influence of $\mathrm{pH}$ on the adsorption can be explained in a better way by an adsorbent characteristic known as the point of zero charge $\left(\mathrm{pH}_{\mathrm{zpc}}\right)$. The $\mathrm{pH}_{\mathrm{zpc}}$ of the active carbons were found to be $>6$ (Fig. 5). Thus values of $\mathrm{pH}_{\mathrm{zpc}}>6$ further indicates that the adsorbents conveniently adsorbed any cationic dye at $\mathrm{pH}$ of the medium greater than this values. A similar trend was reported for the adsorption of cationic CV and MG by activated carbon and malt bagasse, respectively [27,28].

In the case of $\mathrm{Cr}(\mathrm{VI})$, the removal efficiency decreases from 96.19 to $66.64 \%$ with increase in solution $\mathrm{pH}$ from 2.0 to 8.0. The higher removal of $\mathrm{Cr}(\mathrm{VI})$ in acidic $\mathrm{pH}$ range could be explained by the fact that $\mathrm{Cr}(\mathrm{VI})$ exist in the form of several anionic species such as $\mathrm{Cr}_{3} \mathrm{O}_{10}{ }^{2-}, \mathrm{Cr}_{2} \mathrm{O}_{7}{ }^{2-}, \mathrm{CrO}_{4}{ }^{2-}, \mathrm{H}_{2} \mathrm{CrO}_{4}^{-}, \mathrm{HCrO}_{4}^{-}$etc depending on the aqueous solution $\mathrm{pH}$ and concentration [29]. Hence, the observed higher adsorption at acidic medium can be ascribed to the strong electrostatic attraction between positively charged adsorbent and chromate anions. Similarly, the reduced adsorption at basic $\mathrm{pH}$ may presumably be due competitive adsorption between chromate and hydroxyl ions. Also, the zero point charge of the adsorbent reflects that the favourable condition for adsorption of anionic species is the medium having $\mathrm{pH}$ less than 5. Therefore, the initial solution $\mathrm{pH}$ of 2.0 was selected as the optimum $\mathrm{pH}$ value. Earlier works have also reported similar behavior [30,31].

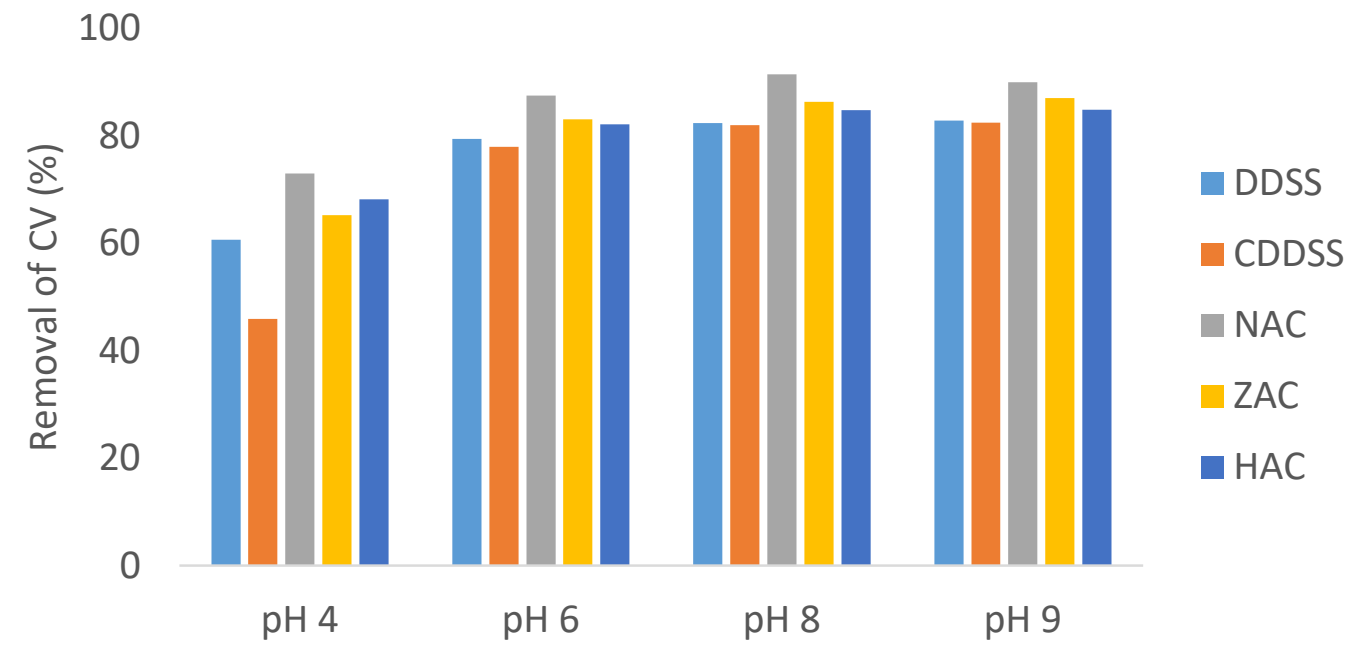

Fig. 6a. Effect of $\mathrm{pH}$ on $\mathrm{CV}$ adsorption onto the adsorbents (Conditions: initial concentration $100 \mathrm{mg} \mathrm{dm}{ }^{-3}$, time 60 min, adsorbent dose $0.2 \mathrm{~g}$, temperature $30^{\circ} \mathrm{C}$, agitation speed $150 \mathrm{rpm}$ )

120

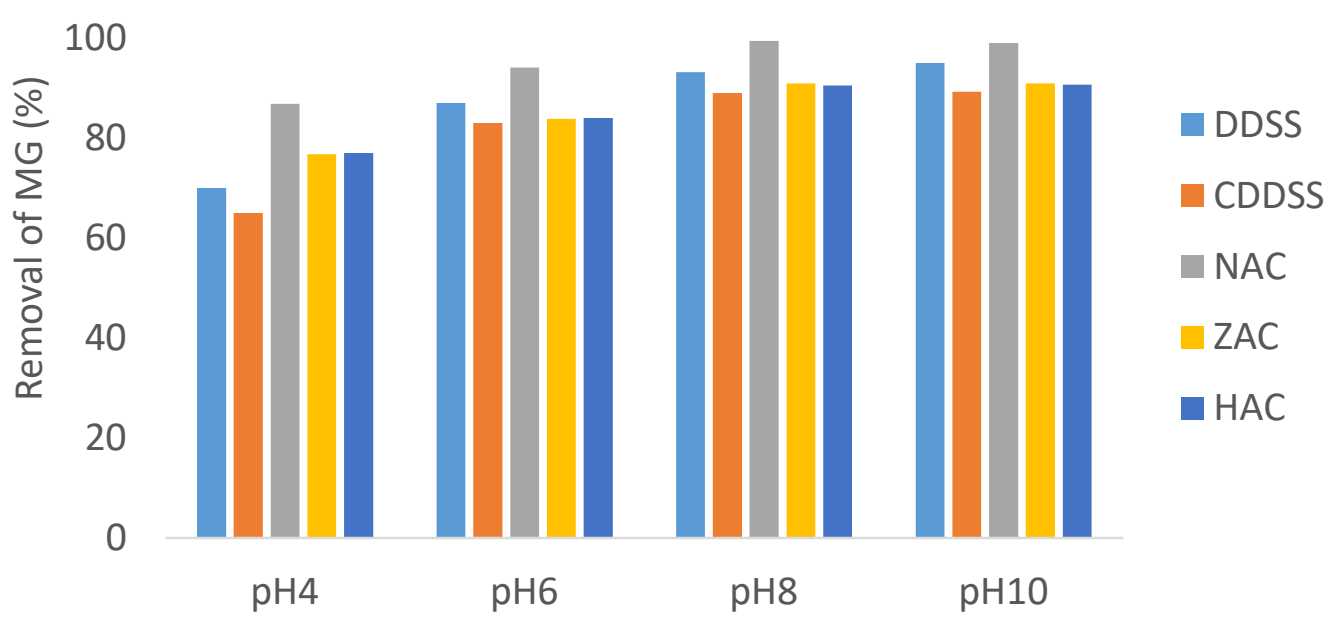

Fig. 6b. Effect of $\mathrm{pH}$ on MG adsorption onto the adsorbents (Conditions: initial concentration $100 \mathrm{mg} \mathrm{dm}^{-3}$, time 60 min, adsorbent dose $0.2 \mathrm{~g}$, temperature $30^{\circ} \mathrm{C}$, agitation speed $150 \mathrm{rpm}$ ) 


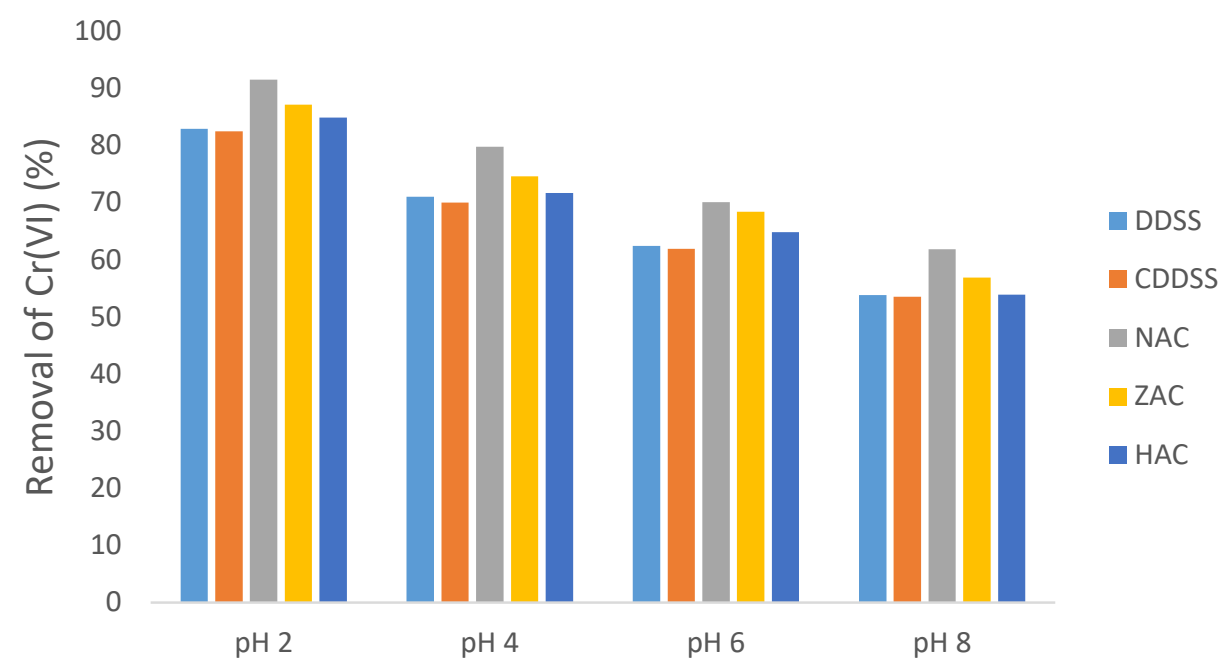

Fig. 6c. Effect of pH on $\mathrm{Cr}(\mathrm{VI})$ adsorption onto the adsorbents (Conditions: initial concentration $100 \mathrm{mg} \mathrm{dm}^{-3}$, time 60 min, adsorbent dose $0.2 \mathrm{~g}$, temperature $30^{\circ} \mathrm{C}$, agitation speed $\left.150 \mathrm{rpm}\right)$

\subsection{Effect of Contact Time}

The adsorption rate is a key factor to design a proper adsorption system. The effect of contact time on the adsorption process is presented in Fig. 7. It is clear from the figures that the adsorption capacity for all the adsorbate first rises rapidly in the early stage, gradually slows down after sometime and lastly becomes almost constant after 50, 60 and 90 min for CV, MG and $\mathrm{Cr}(\mathrm{VI})$ respectively. After attaining the equilibrium, further adsorption was insignificant as a function of contact time under the employed conditions. The rapid uptake at early stage is due to large concentration gradient between the bulk liquid and the solid surface adsorbate concentration. The slow increase at the later stage as reflected by small increase in adsorption capacity was ascribed to low number of unoccupied sites and adsorbate molecules occupy the remaining vacant sites slowly due to repulsive forces between adsorbate molecules of the solid and liquid phases. Similar results have been reported for adsorption of CV dye on sawdust activated carbon [32], MG dye on biochar [33] and Cr(VI) on groundnut shell [34].

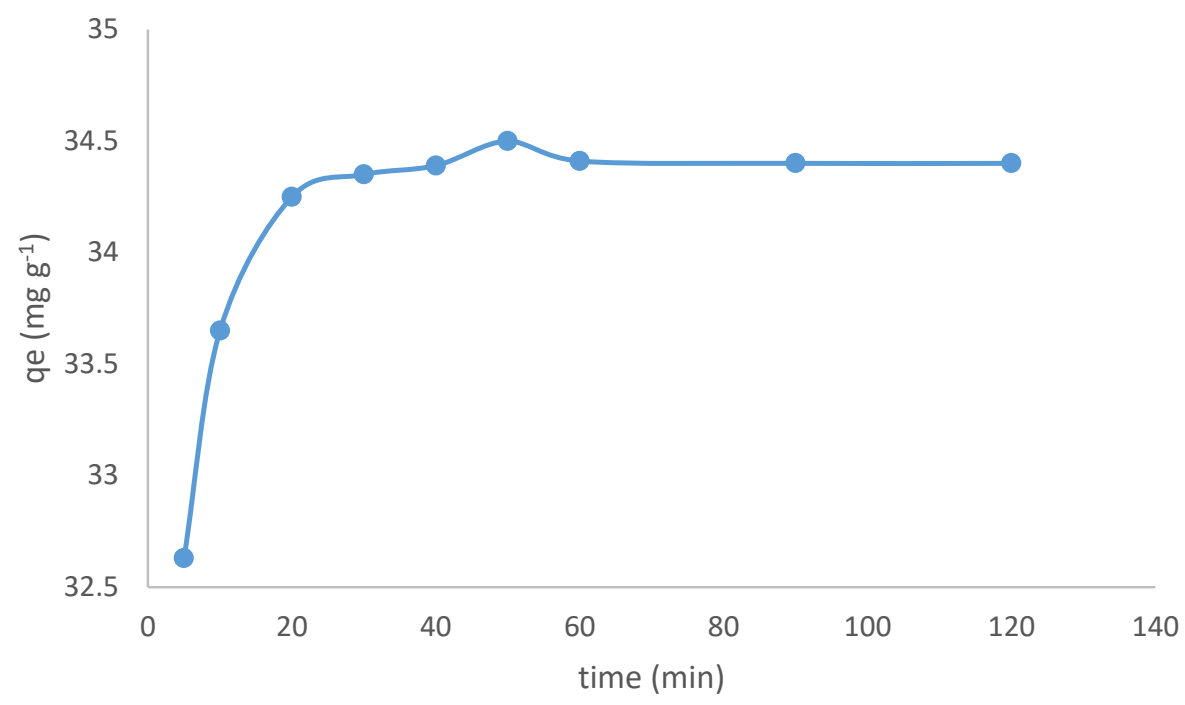

Fig. 7a. Effect of contact time on CV adsorption onto NAC (Conditions: initial concentration $100 \mathrm{mg} \mathrm{dm}^{-3}$, pH 8.0, adsorbent dose $0.15 \mathrm{~g}$, temperature $30^{\circ} \mathrm{C}$, agitation speed $150 \mathrm{rpm}$ ) 


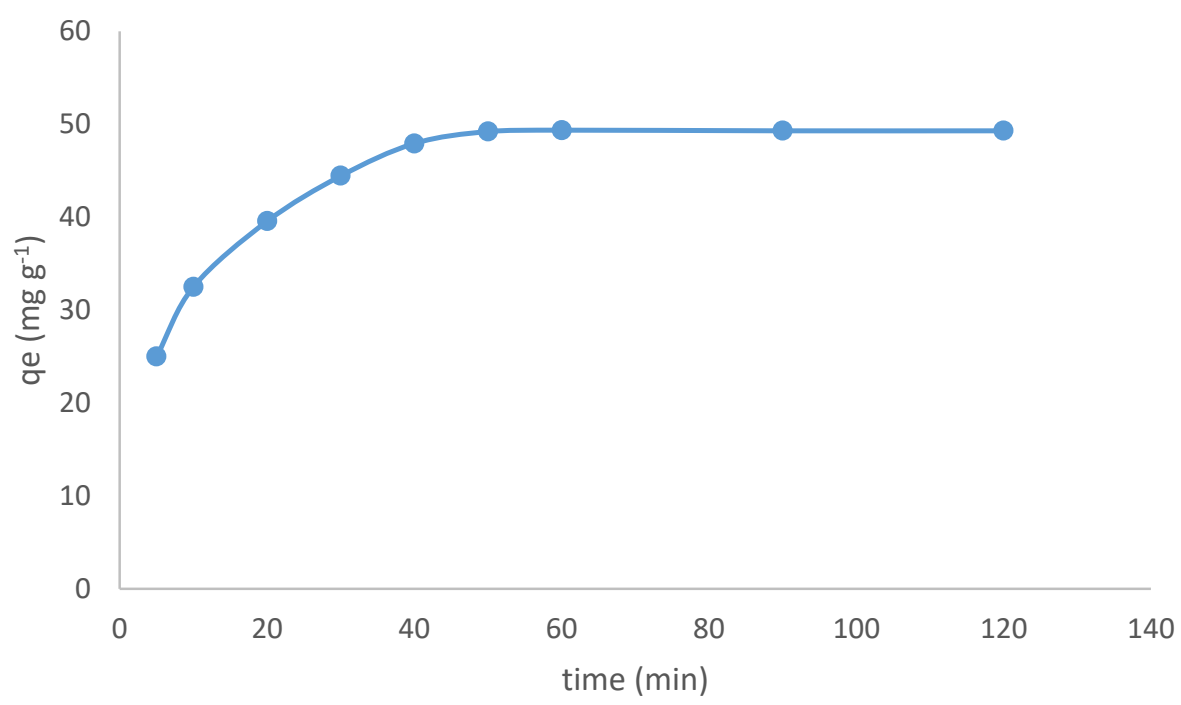

Fig. 7b. Effect of contact time on MG adsorption onto NAC (Conditions: initial concentration $100 \mathrm{mg} \mathrm{dm}^{-3}$, pH 8.0, adsorbent dose $0.15 \mathrm{~g}$, temperature $30^{\circ} \mathrm{C}$, agitation speed $150 \mathrm{rpm}$ )

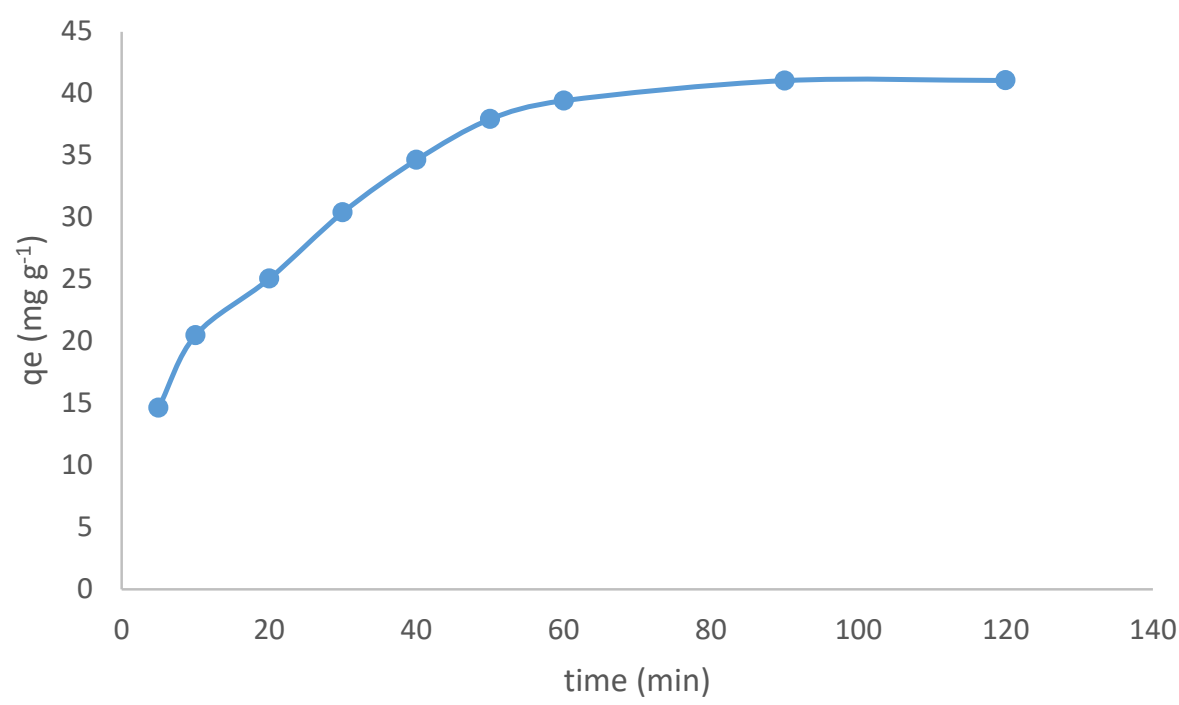

Fig. 7c. Effect of contact time on $\mathrm{Cr}(\mathrm{VI})$ adsorption onto NAC (Conditions: initial concentration $100 \mathrm{mg} \mathrm{dm}^{-3}$, pH 2.0, adsorbent dose $0.15 \mathrm{~g}$, temperature $30^{\circ} \mathrm{C}$, agitation speed $\left.150 \mathrm{rpm}\right)$.

\subsection{Adsorption Kinetics}

Adsorption kinetics is one the key factors that must be understood before the applicability of any sorbent material. It is an important consideration in understanding the adsorption process as it provides information about the adsorbate uptake rate and evidently this rate influence the residence time of solute uptake at the solid-solution interface. It is also the main parameter to consider while designing the sorption system. Kinetics are influenced by adsorbate concentration, surface complexity of the adsorbent and flow. In the past decades, many mathematical models have been developed to describe adsorption data, which can generally be categorized as adsorption diffusion 
models and adsorption reaction models. Both models are employed to analyze the dynamic process of adsorption [35].

The diffusion models are normally formulated on the basis of three successive steps: (1) diffusion of solute across the liquid film surrounding the adsorbent material, i.e film diffusion; (2) diffusion of solute in the pores of the adsorbent, which is so-called intra-particle diffusion; and (3) adsorption of adsorbate on the active site of the adsorbent. However, reaction models originating from chemical reaction kinetics are based on the whole process of adsorption without considering the aforementioned steps [35]. At present, the pseudo-first-order and pseudo-secondorder models have been widely employed in almost every adsorption process to describe the adsorbent-adsorbate interaction. The applicability of any model depends on the error level- Sum of Squared Errors (SSE) or correlation coefficient $\left(\mathrm{R}^{2}\right)$.

Pseudo-first-order model (also known as Lagergren model) describes the sorption of solute following the first order mechanism [36]. It can be represented as follows:

$$
\frac{\mathrm{dqt}}{\mathrm{dt}}=\mathrm{k}_{1}(\mathrm{qe}-\mathrm{qt})
$$

where $\mathrm{q}_{\mathrm{e}}$ and $\mathrm{q}_{\mathrm{t}}\left(\mathrm{mg} \mathrm{g}^{-1}\right)$ represent the adsorption capacities at equilibrium and time $\mathrm{t}(\mathrm{min})$, respectively. $\mathrm{k}_{1}\left(\mathrm{~min}^{-1}\right)$ is the pseudo-first-order rate constant. Integrating Eq. (5) with the boundary conditions of $\mathrm{q}_{\mathrm{t}}=0$ at $\mathrm{t}=0$ and $\mathrm{q}_{\mathrm{t}}=\mathrm{q}_{\mathrm{t}}$ at $\mathrm{t}=\mathrm{t}$ yields:

$$
\log \left(\frac{\mathrm{qe}}{\mathrm{qe}-\mathrm{qt}}\right)=\frac{\mathrm{k}_{1}}{2.303} \mathrm{t}
$$

which can be rearranged to:

$$
\log \left(\mathrm{q}_{\mathrm{e}}-\mathrm{q}_{\mathrm{t}}\right)=\operatorname{loq}_{\mathrm{e}}-\frac{\mathrm{k}_{1}}{2.303} \mathrm{t}
$$

The value of the rate constant, $\mathrm{k}_{1}$ can be estimated by plotting log (qe-qt) againt $\mathrm{t}$.

Pseudo-second-order model assumes that the rate of solute adsorption is directly proportional to the number of available adsorption sites on the adsorbent [37]. It rate expression in differential form is given by:

$$
\frac{\mathrm{dq}}{\mathrm{dt}}=\mathrm{k}_{2}(\mathrm{qe}-\mathrm{qt})^{2}
$$

where $\mathrm{k}_{2}\left(\mathrm{~g} \cdot \mathrm{mg}^{-1} \cdot \mathrm{min}^{-1}\right)$ is the pseudo-second-order rate constant. Applying the integral limits for $\mathrm{t}(0, \mathrm{t})$ and $\mathrm{q}_{\mathrm{t}}(0$, $\mathrm{q}_{\mathrm{t}}$ ), the linearized form of Eq. (8) is:

$$
\mathrm{q}_{\mathrm{t}}=\frac{\mathrm{t}}{\frac{1}{\mathrm{k}_{2 \mathrm{q}_{\mathrm{e}}^{2}}+\frac{\mathrm{t}}{\mathrm{q}_{\mathrm{e}}}}}
$$

Eq. (9) has been rearranged in the form of:

$$
\frac{\mathrm{t}}{\mathrm{qt}}=\frac{1}{\mathrm{k}_{2} \mathrm{qe}^{2}}+\frac{\mathrm{t}}{\mathrm{qe}}
$$

The value of the pseudo-second-order rate constant can be determined from a graph of t/qt against $t$.

The kinetic data so obtained in the present investigation have been fitted on the pseudo-second-order (Fig. 8a) and pseudo-first-order (Fig. 8b) and the relevant parameters associated with these models are incorporated in Table 1. On comparing the values of the correlation coefficient, one can deduce that the kinetic data of all the adsorbates exhibited a very good compatibility with pseudo-second-order model. Also, the comparison of experimental adsorption capacities $\left(\mathrm{q}_{\exp }\right)$ and the predicted values $\left(\mathrm{q}_{\mathrm{cal}}\right)$ showed that the pseudo-first-order model do not satisfactorily explain the kinetic data, whereas the $\mathrm{q}_{\mathrm{cal}}$ obtained from the pseudo-second-order (34.69, 50 and $44.1 \mathrm{mg} \mathrm{g}^{-1}$ ) for the sorption of the adsorbates were close to the $\mathrm{q}_{\exp }\left(34.41,49.3\right.$ and $\left.41.05 \mathrm{mg} \mathrm{g}^{-1}\right)$. Thus, the adsorption systems are more suitably represented by pseudo-second-order model which is based on the assumption that the process rate determining step may be chemisorption involving valence forces through exchange or sharing of electrons between adsorbate and adsorbent. The pseudo-second-order model has been reported to well describe the adsorption of dyes and metals from aqueous solution by various researchers [38,39]. 


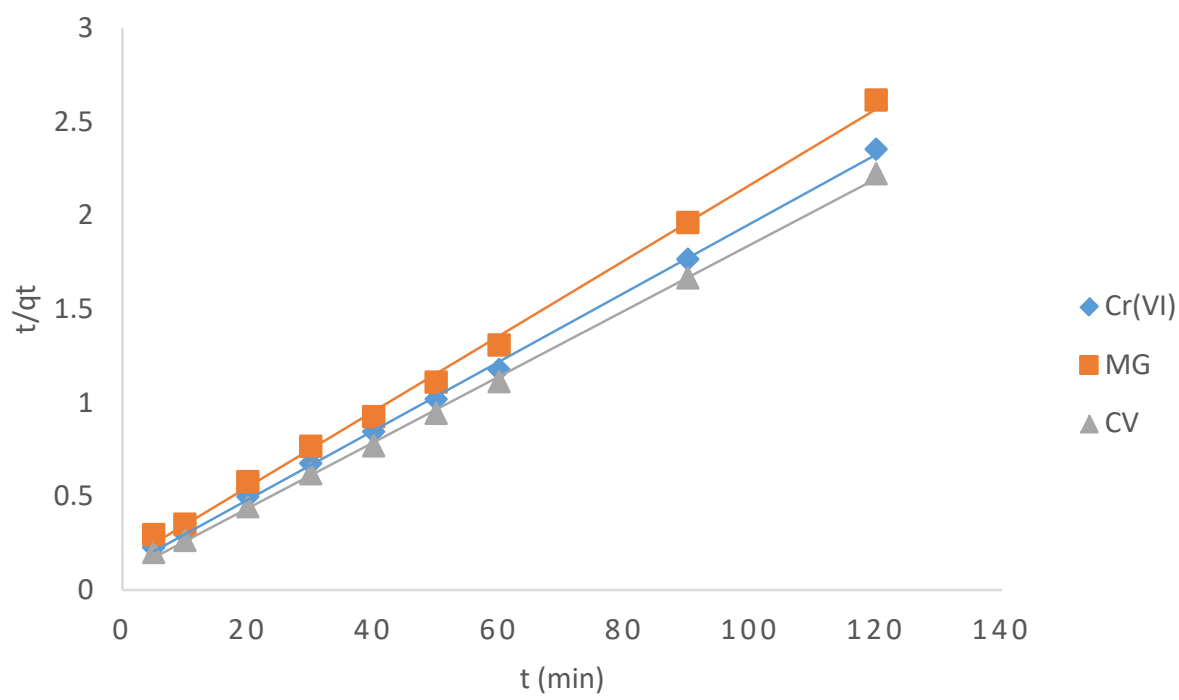

Fig. 8a. Pseudo-second-order kinetic fit for adsorption of adsorbates onto NAC

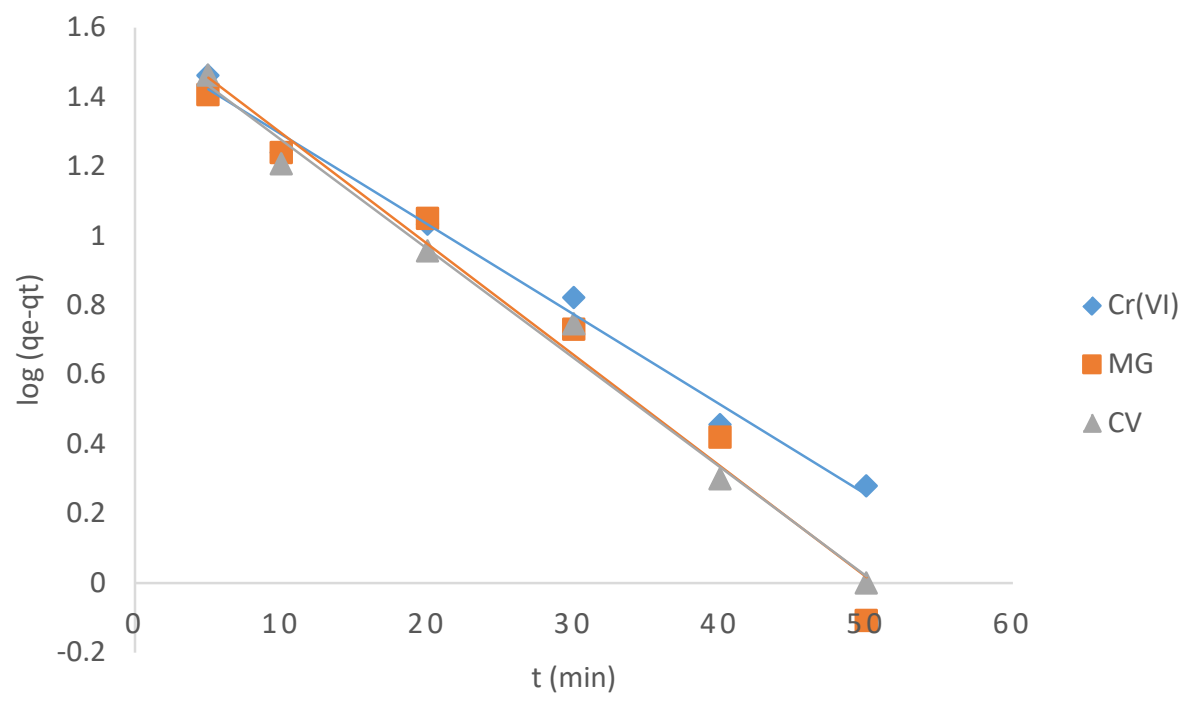

Fig. 8b. Pseudo-first-order kinetic fit for adsorption of adsorbates onto NAC

Table 1. The parameters of different kinetic models for adsorption of adsorbates onto NAC

\begin{tabular}{lllll}
\hline Kinetic model & Parameters & CV & MG & Cr(VI) \\
\hline Pseudo-first-order & $\mathrm{k}_{1}\left(\mathrm{~min}^{-1}\right)$ & 0.13 & 0.08 & 0.03 \\
& $\mathrm{q}_{\text {exp }}\left(\mathrm{mg} \mathrm{g}^{-1}\right)$ & 34.41 & 49.3 & 41.05 \\
& $\mathrm{q}_{\mathrm{e} \mathrm{cal}}\left(\mathrm{mg} \mathrm{g}^{-1}\right)$ & 20.74 & 40.30 & 65.29 \\
& $\mathrm{SSE}(\%)$ & 6.11 & 4.02 & 10.84 \\
& $\mathrm{R}^{2}$ & 0.9879 & 0.9682 & 0.9311 \\
Pseudo-second order & $\mathrm{k}_{2}\left(\mathrm{~g} \mathrm{mg}^{-1} \mathrm{~min}^{-1}\right)$ & 0.10 & 0.003 & 0.001 \\
& $\mathrm{q}_{\text {exp }}\left(\mathrm{mg} \mathrm{g} \mathrm{g}^{-1}\right)$ & 34.41 & 49.30 & 44.05 \\
& $\left.\mathrm{qe} \mathrm{cal} \mathrm{mg} \mathrm{g}^{-1}\right)$ & 34.69 & 50.00 & 44.10 \\
& $\mathrm{SSE}(\%)$ & 0.09 & 0.23 & 0.02 \\
& $\mathrm{R}^{2}$ & 0.9990 & 0.9958 & 0.9996 \\
\hline
\end{tabular}




\subsection{Thermodynamic Investigations}

The thermodynamic parameters are vital for the interpretation of the nature of adsorption process regarding their physicochemical characteristics. Gibbs free energy change $(\Delta \mathrm{G})$, furnish the information of whether the sorption process is spontaneous or not, meaning if an external energy source is required to initiate the adsorption. The enthalpy change $(\Delta \mathrm{H})$ gives an insight about the thermal character of the sorption, indicating whether the process is exothermic or endothermic. Finally, the entropy change $(\Delta \mathrm{S})$ is an indicator of magnitude concerning the affinity between the adsorbate molecules and adsorbent. The change in Gibbs free energy $(\Delta \mathrm{G})$, enthalpy $(\Delta \mathrm{H})$ and entropy $(\Delta S)$ for the adsorption process were determined using the following equations [40]:

$$
\begin{gathered}
\mathrm{K}_{\mathrm{c}}=\frac{\mathrm{C}_{\mathrm{ADS}}}{\mathrm{Ce}} \\
\Delta \mathrm{G}^{\circ}=-\mathrm{RT}_{\ln \mathrm{K}_{\mathrm{c}}} \\
\Delta \mathrm{G}^{\mathrm{o}}=\Delta \mathrm{H}^{\mathrm{o}}-\mathrm{T} \Delta \mathrm{S}^{\mathrm{o}}
\end{gathered}
$$

where, $\mathrm{C}_{\mathrm{ADS}}$ and $\mathrm{C}_{\mathrm{e}}\left(\mathrm{mg} \mathrm{dm}^{-3}\right)$ represent the equilibrium concentration of the adsorbates on the adsorbent and in the liquid phase, respectively, $\mathrm{K}_{\mathrm{c}}$ is the equilibrium constant of adsorption, $\mathrm{R}$ is the gas constant $\left(8.314 \mathrm{~J} \mathrm{~K}^{-1} \mathrm{~mol}^{-1}\right)$ and $\mathrm{T}$ is the temperature (K).

Eq. 12 was used to obtain the values of $\Delta \mathrm{G}^{\circ}$ at different temperatures. The plot of $\Delta \mathrm{G}^{\circ}$ against $\mathrm{T}$ as represented by Eq. 13 was used for the estimation of magnitude of $\Delta \mathrm{S}^{\circ}$ and $\Delta \mathrm{H}^{\circ}$. The estimated values of $\Delta \mathrm{G}^{\circ}, \Delta \mathrm{H}^{\circ}$, and $\Delta \mathrm{S}^{\circ}$ for the sorption process are summarized in Table 2 . The negative values of $\Delta \mathrm{G}$ for all the adsorbates implies that the adsorption phenomenon is spontaneous and had a high feasibility. Decrease in value of $\Delta \mathrm{G}^{\circ}$ with increase in temperature implies that higher temperatures make the adsorption easier. The overall adsorption process appears to be accompanied with absorption of heat from the surroundings i.e endothermic $(\Delta \mathrm{H}=45.24,8.39$ and $29.69 \mathrm{~kJ} \mathrm{~mol}^{-1}$ ) for $\mathrm{CV}$, MG and $\mathrm{Cr}(\mathrm{VI})$ respectively. This may have been because increasing the temperature increased the kinetic energy of the adsorbate molecules, making the interaction between the adsorbent and adsorbate stronger. The data presented in Table 2 also revealed that $\Delta \mathrm{S}$ values were positive for all the adsorbates. This reflects the high affinity of the adsorbent to the adsorbates [41]. Hence, the feasibility of the process depend mainly on the increase in entropy during adsorption. Similar trends in thermodynamics have also been observed for the adsorption of CV onto calcinated waste mussel shells [42], MG onto waste pea shells [43] and $\mathrm{Cr}(\mathrm{VI})$ onto activated carbon [44].

Table 2. The thermodynamic parameters for adsorption of adsorbates onto NAC

\begin{tabular}{lllll}
\hline Adsorbate & Temperature $(\mathrm{K})$ & $\Delta \mathrm{G}\left(\mathrm{kJ} \mathrm{mol}^{-1}\right)$ & $\Delta \mathrm{H}\left(\mathrm{kJ} \mathrm{mol}^{-1}\right)$ & $\Delta \mathrm{S}\left(\mathrm{kJ} \mathrm{mol}{ }^{-1} \mathrm{~K}^{-1}\right)$ \\
\hline CV & 303 & -11.96 & 45.24 & 0.188 \\
& 313 & -13.62 & & \\
& 323 & -14.38 & 8.39 & \\
MG & 333 & -17.65 & & \\
& 303 & -11.45 & & \\
& 313 & -12.18 & 29.70 & 0.125 \\
Cr(VI) & 323 & -12.84 & & \\
& 333 & -13.42 & & \\
& 303 & -8.312 & & \\
& 313 & -9.359 & & \\
\end{tabular}

\subsection{Proposed Adsorption Mechanism}

FTIR spectroscopy was majorly used to elucidate the mechanism of adsorption of the adsorbate molecules on the adsorbent. The FTIR spectroscopic analysis has revealed the presence of polar carboxyl and hydroxyl groups in the adsorbents (Fig. 4). It has been reported that the adsorption of cationic species is majorly due to -OH and $\mathrm{COO}^{-}$functional groups [45]. The FTIR pattern revealed move in the position of $-\mathrm{OH}$ peak after dyes adsorption. Therefore, the adsorption of cationic CV and MG onto the adsorbent might probably be due to strong electrostatic attraction of these polar groups with the charged centers of cationic $\mathrm{CV}\left(\mathrm{CV}^{+} \mathrm{Cl}^{-}\right)$and $\mathrm{MG}\left(\mathrm{MG}^{+} \mathrm{Cl}^{-}\right)$molecules. The influence of $\mathrm{pH}$ is very important in the mechanism since hydroxyl ions and protons take part in the reaction [46]. At 
higher $\mathrm{pH}$ (i.e $>\mathrm{pH}_{\mathrm{zpc}}$ ), the $\mathrm{OH}^{-}$ions concentrate on the adsorbent's surface and accordingly the surface bears a negative charge. Thus, the attachment of the dyes on the adsorbent occurred due to electrostatic attraction of the cationic species with the negatively charged adsorbent containing the aforementioned functional groups (-OH and $\left.\mathrm{COO}^{-}\right)$. The adsorption of dye molecules onto the NAC may be mechanistically postulated as:

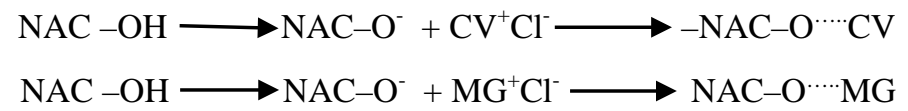

The steps involved are deprotonation of the NAC forming negatively charged centers followed by the binding or attachment of the dye cations. The suggested mechanism is justified by the experimental observation of the relatively poor adsorption at acidic $\mathrm{pH}$. At the lower $\mathrm{pH}$ i.e under acidic condition, the concentration of proton $\left(\mathrm{H}^{+}\right)$would suppress the electrostatic attraction between the adsorbent and adsorbates resulting in the overall decline in adsorption.

The hexavalent chromium removal mechanism may also be attributed to electrostatic attraction between protonated surface sites of NAC $\left(\mathrm{NAC}-\mathrm{OH}_{2}{ }^{+}\right)$and $\mathrm{Cr}$ anions $\left(\mathrm{HCrO}_{4}^{-}\right)$at acidic $\mathrm{pH}$. This can be represented by the following reaction (mailto):

$$
\mathrm{NAC}-\mathrm{OH} \longrightarrow \mathrm{NAC}-\mathrm{OH}_{2}{ }^{+}+\mathrm{HCrO}_{4}^{-} \longrightarrow \mathrm{NAC}-\mathrm{OH}_{2}{ }^{+} \ldots \cdot \mathrm{HCrO}_{4}^{-}
$$

The steps involved are protonation of the hydroxyl groups of NAC at lower $\mathrm{pH}$ (2.0), forming positively charged sites followed by the binding of $\mathrm{Cr}$ anions. The postulated mechanism is reinforced by the experimental observation of the low adsorption of $\mathrm{Cr}(\mathrm{VI})$ at higher $\mathrm{pH}$. At the higher $\mathrm{pH}$ i.e under basic condition, the hydroxyl ions $\left(\mathrm{OH}^{-}\right)$would compete with the $\mathrm{HCrO}_{4}^{-}$for positive binding sites and therefore suppressing the electrostatic attraction between the adsorbent and adsorbate resulting in the overall decline in adsorption.

Thus on the basis of the above findings, the adsorption mechanism of the adsorbates onto the prepared adsorbent can safely be assumed to be involved in the following successive steps: (1) movement of adsorbate molecules from the bulk solution to the NAC surface; (2) diffusion of adsorbate molecules through the pores of the NAC; and (3) adsorption of adsorbates on adsorbent surface by the electrostatic attractive force between the charged sites of sorbate molecules and polar groups of the NAC.

\section{Conclusions}

The major conclusions of this work are drawn as follows:

1. The study established that adsorbents derived from desert date seed shell can be effectively used for the removal of basic dyes and hexavalent chromium from industrial wastewaters.

2. The adsorption behavior depends on the nature of adsorbent and the $\mathrm{NaOH}$ activated carbon (NAC) offered the best removal of the adsorbates among all the adsorbents evaluated.

3. The adsorption efficiency of all the adsorbents is highly dependent on $\mathrm{pH}$ which is best suited for 8.0 in the case of the basic dyes and 2.0 for hexavalent chromium.

4. Experimental kinetic data correlate well with pseudo-second-order rate equation for all the adsorbates used in the present study, suggesting therefore, a chemisorption mechanism.

5. The positive enthalpy change $(\Delta H)$ values confirms the endothermic nature and strong binding of the adsorbates on to the adsorbent surface. Negative values of Gibbs free energy $(\Delta G)$ signify that the adsorption is spontaneous and had high feasibility. Positive values of entropy change $(\Delta S)$ reflect the high affinity of the adsorbent material to the adsorbates.

6. The findings clearly indicate that adsorbent derived from desert date seed shell has a promising potential in environmental applications such as removing hazardous substances from industrial wastewater.

7. The DDSS used in this work are abundantly locally available, require almost no cost, and more important very effective in removing contaminants from aqueous solution. Therefore, the eco-friendly adsorbent is expected to be economically feasible for industrial wastewater treatment.

8. This study provides the preliminary knowledge for the design of a dynamic adsorption process for the removal of basic dyes and hexavalent chromium.

9. Through this work, it is believed that contributions are provided to the scientific investigations about the decontamination of precious water resources. 
10. Future work will have to focus at the understanding of the interactions between the desert date seed shell and the chosen adsorbates. The information acquired in such studies can be employed for the design of operating conditions which could enable improvement in adsorption performances.

\section{Acknowledgements}

The authors are grateful to Malam Musa Beli of Central Research Laboratory, Bayero University Kano. Without his kind support and techniques, the analysis of the samples would not have been so successfully possible.

\section{References}

[1] M. El-Gohary, "Joint Angle Tracking with Inertial Sensors", Ph.D. dissertation, Portland State University, Portland, USA, 2013. doi: 10.15760/etd.661. [1] Hai, F.I., Yamamoto, K. and Fukushi K. (2006). Development of submerged membrane fungi reactor for textile wastewater. Desalination, 192:315-322.

[2] Jadhav, J.P., Kalyani, D.C., Telke, A.A., Phugare, S.S. and Govindwar, S.P. (2010). Evaluation of the efficacy of bacterial consortium for the removal of color, reduction of heavy metals, and toxicity from textile dye effluent. Bioresource Technology, 101:165-173.

[3] Ahmad, R. (2009). Studies on Adsorption of Crystal Violet Dye from Aqueous Solution onto Coniferous pinus Bark Powder (CPBP). Journal of Hazardous Materials, 171:767-773.

[4] Raval, N.P., Shah, P.U. and Shah, N.K. (2017). Malachite Green ‘ a Cationic Dye’ and its Removal from Aqueous Solution by Adsorption. Applied Water Science, 7:3407-3445.

[5] Gupta, S. and Babu, B. V. (2009). Removal of Toxic Metal Cr(VI) from Aqueous Solution using Sawdust as Adsorbent: Equilibrium, Kinetics and Regeneration Studies. Chemical Engineering Journal. 150:1 352-365.

[6] Bello, O.S., Adegoke, K.A., Olaniyan, A.A. and Abdulazeez, H. (2013). Dye adsorption using biomass wastes and natural adsorbents: overview and future prospects. Desalination and Water Treatment. 1-24.

[7] Senol, Z.M. and Simsek, S. (2020). Removal of Pb2+ ions from aqueous medium using chitosan-diatomite composite: equilibrium, kinetic and thermodynamic studies. Journal of the Turkish Chemical Society Section A: Chemistry. 7(1):307318.

[8] Yunusa, U. and Ibrahim, M.B. (2020). Equilibrium and thermodynamic studies on adsorption of hexavalent chromium from aqueous solution onto low cost activated carbon. International Journal of Engineering and Manufacturing (IJEM), 10(2):5270 .

[9] Yunusa, U. and Ibrahim, M.B. (2019). Reclamation of Malachite Green-Bearing Wastewater Using Desert Date Seed Shell: Adsorption Isotherms, Desorption and Reusability Studies. Chemsearch Journal. 10(2):112-122.

[10] Ali, I., Peng, C., Khan, Z.M., Sultan, M., Naz, I., Ali, M., Farid, H.U., Mahmood, M.H. and Ahsen, R. (2019). Removal of Crystal Violet and Eriochrome Black T Dye from Aqueous Solution by Magnetic Nanoparticles Biosynthesized from Leaf Extract of Fraxinus Chinensis Roxb. Polish Journal of Environmental Studies, 28(4):2027-2040.

[11] Mashkoor, F., Nasar, A., Inamuddin, and Asiri, A.M. (2018). Exploring the reusability of synthetically contaminated wastewater containing crystal violet dye using Tectona grandis sawdust as a very low-cost adsorbent. Scientific Reports, 8(1):8314.

[12] Adeyi, A.A., Siti, N.A.M.J., Abdullah, L.C., Choong T.S.Y., Lau, K.L., and Abdullah, M. (2019b). Simultaneous adsorption of cationic dyes from binary solutions by Thiourea-Modified Poly(acrylonitrile-co-acrylic acid): detailed isotherm and kinetic studies. Materials, 12 (2903):1-21.

[13] Sriram, G., Uthappa, U.T., Kigga, M., Jung, H., Altalhi, T., Brahmkhatri, V. and Kurkuri, M. (2019). Xerogel activated diatom as an effective hybrid adsorbent for the efficient removal of malachite green. New Journal of Chemistry. 43:38103820 .

[14] Asadullah, Kaewsichan L, Tohdee K. (2019). Adsorption of hexavalent chromium onto alkali-modified biochar derived from Lepironia articulata: a kinetic, equilibrium, and thermodynamic study. Water Environment Research;1-14.

[15] Labied, R., Benturki, O., Hamotouche, A. and Donnot, A. (2018). Adsorption of hexavalent chromium by activated carbon obtained from a waste lignocellulosic material (Ziziphus jujuba cores): kinetic, equilibrium, and thermodynamic study. Adsorption Science and Technology 36(3-4):1066-1099.

[16] Wang, X., Wang, S., Yin, X., Chen, J. and Zhu, L. (2014). Activated carbon preparation from cassava residue using a twostep $\mathrm{KOH}$ activation: preparation, micropore structure and adsorption capacity. Journal of Biobased Materials and Bioenergy, 8(20):1-8.

[17] Bakatula, E.N., Richard, D., Neculita, C.M. and Zagury, G.J. (2018). Determination of point of zero charge of natural organic materials. Environmental Science and Pollution Research, 25(8):7823-7833.

[18] Ahmad, M. A., Ahmad, N. and Bello, O. S. (2014). Adsorptive Removal of Malachite Green Dye Using Durian Seed-Based Activated Carbon. Water Air Soil Pollution. 225:1-18. 
[19] Chowdhury, S., Chakraborty, S. and Das, P. (2013). Adsorption of crystal violet from aqueous solution by citric acid modified rice straw: equilibrium, kinetics and thermodynamics. Separation Science and Technology, 48:1339-1348.

[20] Khan, M.M.R., Rahman, M.W. and Cheng, C.K. (2015). Tea dust as potential low-cost adsorbent for the removal of crystal violet from aqueous solution. Desalination and Water Treatment. 57(31):14728-14738.

[21] Werkneh, A.A., Habtu, N.G. and Beyene, H.D. (2014). Removal of hexavalent chromium from tannery wastewater using activated carbon primed from sugarcane bagasse: adsorption/desorption studies. American Journal of Applied Chemistry 2(6): 128-135.

[22] Mukherjee, A. Zimmerman, A.R. and Harris, W. (2011). Surface chemistry variations among a series of laboratoryproduced biochars. Geoderma, 163(3):247-255.

[23] Mahmood, T. Saddique, M.T., Naeem, A., Westerhoff, P. Mustafa, S. and Alum, A. (2011). Comparison of different methods for the point of zero charge determination of NiO. Industrial and Environmental Chemistry Research, 50:1001710023.

[24] Abbas, M., Harrache, Z. and Trari, M (2019). Removal of Gentian Violet in Aqueous Solution by Activated Carbon Equilibrium, Kinetics, and Thermodynamic Study. Adsorption Science \& Technology 37(7-8):566-589.

[25] Banerjee, S., Sharma, G.C., Gautam, R. K., Chattopadhyaya, M.C., Upadhyay, S. N., and Sharma, Y. C. (2016). Removal of malachite green, a hazardous dye from aqueous solutions using Avena sativa (oat) hull as a potential adsorbent. Journal of Molecular Liquids. 213:162-172.

[26] Rammel, R.S., Zatiti, S.A. and EL Jamal M.M. (2011). Biosorption of crystal violet by Chaetophora elegans alga. Journal of the University of Chemical Technology and Metallurgy. 46(3):283-292.

[27] Savithri S., Rajeshwari, M., Nandhakumar, V., Durgadevi, K. and Chandramohan M. (2019). Adsorptive removal of crystal violet dye from aqueous solution using activated carbon prepared from Cassia fistula (L) fruit shell. Research Journal of Chemistry and Environment, 23(9):71-75.

[28] Reis, H. C. O., Cossolin, A. S., Santos, B. A. P., Castro, K. C., Pereira, G. M., Silva, V. C., Sousa, P. T., Dall’Oglio, E. L., Vasconcelos, L. G. and Morais E. B. (2018). Malt bagasse waste as biosorbent for malachite green: an ecofriendly approach for dye removal from aqueous solution. International Journal of Biotechnology and Bioengineering. 12(4):118-126.

[29] Zhao, Y., Yang, S., Ding, D., Chen, J., Yang, Y., Lei, Z., Feng, C. and Zhang, Z. (2013). Effective adsorption of cr(vi) from aqueous solution using natural akadama clay. Journal of Colloid and Interface Science, 395:198-204.

[30] Kumar, G.V.S.R.P., Avinash, M.K., Bharath, Y., and Rao, K.S. (2019). Removal of hexavalent chromium from aqueous solution using low cost adsorbents and ANN modelling for prediction. Journal of Indian Chemical Society, 96:1-8.

[31] Parlayici, S. and Pehlivan, E. (2019). Comparative study of $\operatorname{Cr}(\mathrm{VI})$ removal by bio-waste adsorbents: equilibrium, kinetics and thermodynamic. Journal of Analytical Science and Technology, 10(15):1-8.

[32] Gupta, T. B. and Lataye, D. H. (2019). Removal of crystal violet and methylene blue dyes using Acacia nilotica sawdust activated carbon. Indian Journal of Chemical Technology.26: 52-68.

[33] Yong S. K., Zaid, M.K.Z., Jamion, N. A. and Omar, Q. (2017). Sorption of malachite green by cassava stem biochar: kinetic and isotherm studies. Journal of Fundamental and Applied Sciences. 9(6S):273-287.

[34] Bayuo, J., Pelig-Ba, K.B. and Abukari, M.A. (2019). Adsorptive removal of chromium(VI) from aqueous solution unto groundnut shell. Applied Water Science, 9(107):1-11.

[35] Qiu, H., LV, L., Pan, B., Zhang, Q., Zhang, W., Zhang, Q. (2009). Critical review in adsorption kinetic models. Journal of Zhejiang University SCIENCE A. 10(5):716-724.

[36] Langergren, S. (1898). About the theory of so-called adsorption of soluble substances Band. 24(4):1-39.

[37] Ho, Y.S. and McKay, G. (1999). Pseudo-second-order model for sorption processes. Process Biochemistry. 34:451-465.

[38] Cheruiyot, G.K., Wanyonyi, W.C., Kiplimo, J.J. and Maina, E.N. (2019). Adsorption of toxic crystal violet dye using coffee husks: equilibrium, kinetics and thermodynamics study. Scientific African 5 (e00116):1-11.

[39] Rai, M.K., Shahi, G., Meena, R., Meena, S., Chackraborty, S., Singh, R.S and Rai. B.N (2016) Removal of hexavalent Cr (VI) using activated carbon prepared from mango kernel activated with H3PO4. Resource-Efficient Technologies, 2:S63S70.

[40] Ma, J., Yu, F., Zhou, L., Jin, L., Yang, M., Luan, J., Tang, Y., Fan, H., Yuan, Z. and Chen, J. (2012). Enhanced adsorptive removal of methyl orange and methylene blue from aqueous solution by alkali-activated multiwalled carbon nanotubes. Applied Materials and Interfaces, 4:5749-5760.

[41] Sharma. P.K., Ayub, S. and Tripath, C.N. (2016). Isotherms describing physical adsorption of cr(vi) from aqueous solution using various agricultural wastes as adsorbents. Cogent Engineering 3:1-20.

[42] Dandil, S., Sahbaz, D.A, and Acikgoz, C. (2019). High performance adsorption of hazardous triphenylmethane dye-crystal violet onto calcinated waste mussel shells. Water Quality Research Journal. 54(3): 249-256.

[43] Khan, T.A., Rahman, R., Ali, I., Khan, E.A. and Mukhlif, A.A. (2014). Removal of malachite green from aqueous solution using waste pea shells as low-cost adsorbent _ adsorption isotherms and dynamics. Toxicological \& Environmental Chemistry, 96(4):569-578.

[44] Rai, M.K., Giri, B.S., Nath Y., Bajaj, H., Soni, R.P., Singh, R.S. and Rai., B.N. (2018). Adsorption of Hexavalent Chromium from Aqueous Solution by Activated Carbon Prepared from Almond Shell: Kinetics, Equilibrium and Thermodynamics Study. Journal of Water Supply: Research and Technology, 67(8):724-737.

[45] Mashkoor F, Nasar A, Inamuddin, Asiri AM. Exploring the reusability of synthetically contaminated wastewater containing crystal violet dye using Tectona grandis sawdust as a very low-cost adsorbent. Scientific Reports. 2018;8:8314. 
[46] Miretzky, P. and Cirelli, F.A. (2010). Cr(VI) and Cr(III) removal from aqueous solution by raw and modified lignocellulosic materials: A review. Journal of Hazardous Materials. 180:1-9.

\section{Authors’ Profiles}

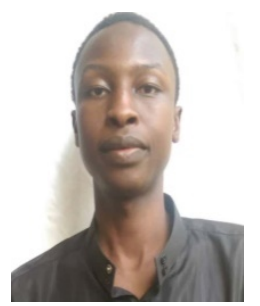

Umar Yunusa received the Bachelor's degree in Chemistry from Ahmadu Bello University, Zaria, Kaduna, Nigeria, and the Master's degree in Chemistry with specialization in Physical Chemistry from Bayero University, Kano. He has about 4 years' experience in teaching and research. He is a member of the chemical society of Nigeria. His areas of research interest is environmental pollution and remediation studies using adsorption technique.

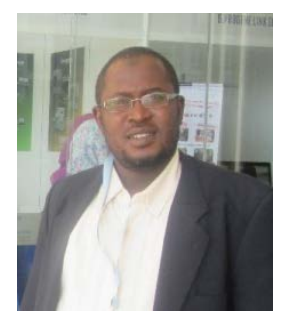

Bishir Usman obtained PhD (Physical and Theoretical Chemistry) in 2015 from the Universiti Teknologi Malaysia. His research focusses on the development of theoretical and computational methods and models to study chemical processes that are related to material science, corrosion studies, Quantitative Structure Activity Relationship, Molecular Mechanics and Molecular Docking. He also conducted research in Kinetics of Biogas production, Biodiesel, Bioethanol and Bio-Hydrogen for energy production. He has many publications in ISI and Scopus index.

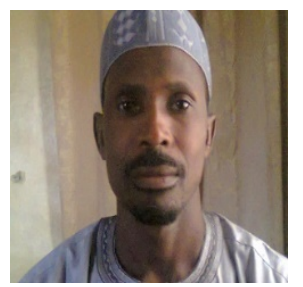

Muhammad Bashir Ibrahim is an energetic professor of physical chemistry currently working with Bayero University, Kano, Nigeria. He has over 25 years' experience in teaching and Research. He is member of professional bodies like the Chemical Society of Nigeria (CSN) and Institute of Chartered Chemist of Nigeria (ICCON). He has over 50 scholarly publications in reputable journals. His area of research interest include wastewater treatment, corrosion control and biophysical researches of biomacromolecules.

How to cite this paper: Umar Yunusa, Bishir Usman, Muhammad Bashir Ibrahim, " Adsorptive Removal of Basic Dyes and Hexavalent Chromium from Synthetic Industrial Effluent: Adsorbent Screening, Kinetic and Thermodynamic Studies ", International Journal of Engineering and Manufacturing (IJEM), Vol.10, No.5, pp.54-74, 2020. DOI: 10.5815/ijem.2020.04.05 